\title{
Article
}

\section{Simultaneous description of equilibrium, interfacial and transport properties of fluids using a Mie Chain Coarse-Grained Force Field.}

\author{
Hai HOANG, Stephanie Delage-Santacreu, and Guillaume Galliero
}

Ind. Eng. Chem. Res., Just Accepted Manuscript • DOI: 10.1021/acs.iecr.7b01397 • Publication Date (Web): 20 Jul 2017

Downloaded from http://pubs.acs.org on July 25, 2017

\section{Just Accepted}

"Just Accepted" manuscripts have been peer-reviewed and accepted for publication. They are posted online prior to technical editing, formatting for publication and author proofing. The American Chemical Society provides "Just Accepted" as a free service to the research community to expedite the dissemination of scientific material as soon as possible after acceptance. "Just Accepted" manuscripts appear in full in PDF format accompanied by an HTML abstract. "Just Accepted" manuscripts have been fully peer reviewed, but should not be considered the official version of record. They are accessible to all readers and citable by the Digital Object Identifier (DOI®). "Just Accepted" is an optional service offered to authors. Therefore, the "Just Accepted" Web site may not include all articles that will be published in the journal. After a manuscript is technically edited and formatted, it will be removed from the "Just Accepted" Web site and published as an ASAP article. Note that technical editing may introduce minor changes to the manuscript text and/or graphics which could affect content, and all legal disclaimers and ethical guidelines that apply to the journal pertain. ACS cannot be held responsible for errors or consequences arising from the use of information contained in these "Just Accepted" manuscripts. 


\title{
Simultaneous description of equilibrium, interfacial and transport
} properties of fluids using a Mie Chain Coarse-Grained Force Field

\author{
Hai Hoang ${ }^{1,2}$, Stéphanie Delage-Santacreu ${ }^{3}, \underline{\text { Guillaume Galliero }}^{1 *}$ \\ ${ }^{1}$ CNRS/TOTAL/UNIV PAU \& PAYS ADOUR, LABORATOIRE DES FLUIDES COMPLEXES \\ ET LEURS RESERVOIRS-IPRA, UMR5150, 64000, PAU, France \\ ${ }^{2}$ Institute of Research and Development, Duy Tan University, Da Nang, Viet Nam \\ ${ }^{3}$ CNRS/UNIV PAU \& PAYS ADOUR, LABORATOIRE DE MATHEMATIQUES ET DE \\ LEURS APPLICATIONS DE PAU-IPRA, UMR5142, 64000, PAU, France \\ *guillaume.galliero@,univ-pau.fr
}

\begin{abstract}
In this work, we propose an unequivocal top-down strategy to build state independent coarse grained force fields based on the homonuclear Mie chain model. Then, this approach is applied to predict thermophysical properties (equilibrium, interfacial and transport) of nonassociating fluids from molecular simulations. Following the seminal work of Mejia et al. [Ind. Eng. Chem. Res. 53, 4131, (2014)], the proposed top-down strategy is based on an extended corresponding states principle (i.e. requiring the critical temperature, one saturated liquid density and the acentric factor for each compound) enriched by the introduction of one reference viscosity in the parameterization procedure. Molecular simulations of the sodeveloped coarse grained model representing various pure fluids (Noble gas, n-alkanes, $\mathrm{H}_{2} \mathrm{~S}$, $\mathrm{CO}_{2} \ldots$ ) yield excellent results on the whole vapor-liquid equilibrium curve. Critical points, saturated densities, vapor pressures and surface tensions are accurately predicted. Saturated liquid viscosities are as well correctly predicted, which is an improvement over previous similar coarse grained models. Using classical Lorentz-Berthelot combining rules, simulations results of the pressure-composition phase diagrams of Noble gases mixtures are in good


agreement with the experimental ones without additional parameterization. In addition, predictions of densities and viscosities of some liquid binary mixtures of hydrocarbons, including asymmetric ones $\left(\mathrm{CH}_{4}+\mathrm{nC}_{10}\right)$ for pressure up to $100 \mathrm{MPa}$, are as good as those obtained on pure fluids. Last, the proposed coarse grained model is able to provide Soret coefficients of $\mathrm{Ar}-\mathrm{Kr}$ and $\mathrm{nC}_{5}-\mathrm{nC}_{10}$ mixtures with a good accuracy. All these results confirm the consistency and the robustness of the proposed approach. 


\section{Introduction}

Accurate estimates of thermophysical (equilibrium, interfacial and transport) properties of fluids play a crucial role in many fields, in particular in chemical and petroleum engineering, and so have been the subject of many developments [1-3]. Among them, molecular modeling based on classical force fields combined with both theories and simulations [4-6] has shown to be a promising way to predict thermophysical properties of fluids $[3,7]$. The present work is a contribution to this field.

Within the molecular modeling approaches, two main families of classical force fields are available in the literature. Force fields based on an as realistic as possible representation of the molecules, so called Fine Grained (FG, i.e. atomistic resolution) models [4-7], and force fields based on a simplified representation of the molecules in which a lot of internal degrees of freedom are safely removed, so called Coarse Grained (CG) models [8-14]. Even if, $a$ priori, FG models should be the preferable option, CG models possess some interesting features. First, CG force fields are far less demanding in terms of CPU time than FG models because of their reduced degree of complexity. This aspect is still important in an engineering perspective, in particular when dealing with multicomponent/multiphasic systems, such as those encountered in the oil and gas industry [15-17], or when dealing with complex transport properties such as thermodiffusion [18-20]. Second, the number of parameters per molecule being small the parameterization of a CG model for a given application can be straightforward as it will be shown in this article. Last, when chosen appropriately, the CG model can be combined with theories, or correlations, removing the need of performing molecular simulations to obtain some of its thermophysical properties [6, 21-29].

Several strategies are available in the literature for developing Coarse Grained model [11-12]. Among them, CG model based on a rigorous bottom-up scheme (i.e. CG models 
developed on the basis of a FG model) are be very promising for general purpose [11-12, 3034]. For thermophysical fluid properties predictions, CG models based on a top-down parameterization strategy (i.e. CG models developed from macroscopic observables), despite being more heuristic, have shown to be very interesting [15, 35-38]. Among them, it seems that the four parameters Mie chain model is one of the best compromises to describe simultaneously equilibrium and interfacial thermophysical properties [15, 29, 36-37]. Therefore, in this work, we have selected the Mie Chain Coarse Grained (MCCG) model.

Two main procedures are available to define the top-down parameterization of a CG model. The first one relies on a minimization between target experimental data (usually vapor-liquid equilibrium data) and those predicted by molecular simulations or an equation of state $[7,12,35,37-40]$. The second one is based on the Corresponding States (CS) [41] framework which allows to directly relate the CG parameters to a limited set of characteristics thermophysical properties such as the critical properties and the acentric factor [36, 41-43]. This CS strategy, which has already been applied to the MCCG model $[36,44]$, is very promising, but some aspects can be further improved in particular when dealing with transport properties. It will be shown in this article how, when using one data of a liquid viscosity in a CS procedure, it is possible to efficiently parameterize the MCCG model so as to describe thermophysical properties of target fluids including not only equilibrium properties but also complex transport properties.

The article is organized as follows. In Sect. II, some details are provided on the force field associated and on the molecular simulations. The top-down parameterization strategy is described in Sect. III. Then, in Sect. IV are discussed the results provided by the MCCG model when applied to describe various fluids and properties. Finally, the main results are summarized in Sect. V, which forms the conclusion. 


\section{Simulation details}

\section{Coarse Grained molecular model}

The Coarse Grained molecular model used in this work consists in a simple homonuclear chain composed of $N$ spheres ( $N$ varying from 1 to 8 in this work) which are freely and tangentially bonded. Two adjacent spheres in a chain are linked by a rigid bond. The interaction between two non-bonded spheres $i$ and $j$ is described by the Mie $\lambda-6$ potential [45]:

$$
u_{M i e}\left(r_{i j}\right)=C_{\lambda} \varepsilon_{i j}\left[\left(\frac{\sigma_{i j}}{r_{i j}}\right)^{\lambda_{i j}}-\left(\frac{\sigma_{i j}}{r_{i j}}\right)^{6}\right]
$$

where $\varepsilon_{i j}$ is the potential well depth, $\sigma_{i j}$ is the collision diameter and $r_{i j}$ the distance between the two spheres. $\lambda_{i j}$, which varies from 8 to 36 in this work, is the exponent characterizing the repulsive interactions between non-bonded spheres and $C_{\lambda}$ is a normalization factor defined by:

$$
C_{\lambda}=\left(\frac{\lambda_{i j}}{\lambda_{i j}-6}\right)\left(\frac{\lambda_{i j}}{6}\right)^{6 /\left(\lambda_{i j}-6\right)}
$$

When dealing with mixtures, the cross-interactions parameters, $\lambda_{i j}, \sigma_{i j}$ and $\varepsilon_{i j}$ between spheres $i$ and $j$ belonging to different molecules have to be defined. For that purpose, many combining rules have been proposed in the literature $[4,7,15,46-48]$. In this work, we have used the classical Lorentz-Berthelot combining rules to deduce $\sigma_{i j}$ and $\varepsilon_{i j}[4,7,15,46-$ 48]:

$$
\begin{gathered}
\sigma_{i j}=\frac{\left(\sigma_{i i}+\sigma_{j j}\right)}{2} \\
\varepsilon_{i j}=\sqrt{\varepsilon_{i i} \varepsilon_{j j}}
\end{gathered}
$$


and the repulsion exponent of the cross-interactions, $\lambda_{i j}$, has been evaluated using an arithmetic average as:

$$
\lambda_{i j}=\frac{\lambda_{i i}+\lambda_{j j}}{2}
$$

It should be pointed out that when dealing with mixtures in which the molecular interaction parameters differ strongly from each other, the LB rules could be insufficient and other combing rules or adjustable coefficients may be required [46-47].

To define dimensionless properties of the MCCG model, noted with a star as superscript in the following, we have used the classical relations [4] given by:

$$
T^{*}=\frac{k_{B} T}{\varepsilon}, \rho^{*}=\rho_{n} \sigma^{3} \text { and } P^{*}=\frac{P \sigma^{3}}{\varepsilon}
$$

where, $k_{B}$ is the Boltzmann constant, $T$ the temperature, $\rho_{n}$ the number density and $P$ the pressure.

\section{Properties computation}

To determine the liquid-vapor phase equilibria properties (saturated density, vapor pressure) of the Mie chain fluids, we have performed Monte Carlo simulations in the Gibbs Ensemble (GEMC) [49-50]. The configurational-bias Monte Carlo method has been applied to deal with the transfer move of long chains $[5,51]$. Between 400 and 1000 molecules have been used and simulations have been performed with a cutoff radius equal to $4.5 \sigma$ with long range corrections included. Properties have been evaluated from averages, using between $2 \times 10^{8}$ and $10^{9}$ moves. To determine the location of the critical point, a classical scaling procedure [52-53] has been applied. Surface tension has been computed from the saturated densities and critical point location combined with the universal relation provided by Galliero 
[53-54]. It should be noticed that the use of such relation may introduce slight deviations, of few percent, from direct computation of surface tension [53].

To compute thermodynamic derivative properties, Monte Carlo simulations in the isobaric-isothermal ensemble have been carried out. Isothermal compressibility and coefficient of thermal expansion have been computed during the simulation from the fluctuations $[7,55]$. The isobaric heat capacity is obtained as the sum of the residual heat capacity and the ideal heat capacity, in which the former is determined from the Monte Carlo simulations $[7,55]$ and the latter is taken from NIST database [56]. The sound velocity is calculated from a classical thermodynamic relation between these quantities.

Molecular dynamics simulations have been performed to compute transport properties, i.e. shear viscosity and thermal diffusion. For that purpose, the reverse Non-Equilibrium Molecular Dynamics (NEMD) scheme proposed by Müller-Plathe [57] has been applied with the parameterization described in Refs. [23-24]. In all NEMD simulations, a cutoff radius equal to $3.5 \sigma$ has been used and long range corrections have been included [4-5]. To constrain the bond length, we have used the classical RATTLE algorithm [58]. When required, temperature and pressure have been controlled using a Berendsen approach [59]. From 3000 to 4000 spheres with runs of at least $2 \times 10^{7}$ time steps and up to $10^{8}$ time steps have been used to perform the computations.

For sake of clarity, the error bars have been omitted in the figures as they are generally smaller than the symbol size. 


\section{Parameterization}

\section{Proposed strategy}

For the parameterization of the Mie Chain Coarse Grained model, we have relied on a top-down strategy [12] similar to that of Mejia et al. [36], i.e. a corresponding states strategy, to unequivocally deduce the MCCG parameters $(\varepsilon, \sigma, N, \lambda)$ from easily available fluid thermophysical properties of the target species.

As it naturally emerges from a dimensional analysis and is well known from the corresponding states framework $[6,41,60]$, a temperature can be used to determine the potential depth, $\varepsilon$, and a volume (or equivalently a density) can be used to determine the collision diameter, $\sigma$. In this work, the critical temperature, $T_{c}$, is used to determine $\varepsilon$ and the saturated liquid density at a reduced temperature $\left(T_{r}=T_{c} / T\right)$ equals to 0.7 , noted $\rho_{s a t, l}$, is used to determine $\sigma$, following what proposed in Mejia et al. [36].

Regarding the determination of the two additional parameters of the MCCG model, the chain length, $N$, and the repulsion exponent, $\lambda$, we have chosen to use the acentric factor and a reference viscosity. The acentric factor [61] is defined by:

$$
\omega=-\log _{10}\left(\frac{P_{v a p}}{P_{c}}\right)-1
$$

where $P_{v a p}$ is the vapor pressure at $T_{r}=0.7$. The reference viscosity, which is similar to the characteristic viscosity proposed by Willman and Teja [62], is defined as:

$$
\mu^{r}=\mu_{s a t, l}\left[\frac{M}{\rho_{s a t, l}^{4}\left(0.7 k_{B} T_{c}\right)^{3}}\right]^{1 / 6}
$$

where $\mu_{s a t, l}$ is the saturated liquid viscosity at $T_{r}=0.7$ and $M$ is the molecular mass. 
The rationale for choosing $\omega$ and $\mu^{r}$ to parameterize the MCCG model is the following. First, the acentric factor is a quantity which is known to be very sensitive to chain length, $N[36,53]$, whereas the liquid viscosity is known to be strongly dependent to the repulsion exponent, $\lambda$ [63-65]. Second, the acentric factor has shown to be valuable to quantify volumetric deviations induced by non-sphericity and is so widely employed in the literature $[1,41]$. Third, the liquid viscosity is a transport property whereas the three other quantities used to parameterize the MCCG model, $T_{c}, \rho_{s a t, l}$ and $\omega$, are equilibrium properties. This is an important feature as the introduction of one transport property in a force field parameterization has proved to be efficient [38, 66-69]. Furthermore, the liquid viscosity is known to scale with the residual (sometimes called "excess") entropy [24, 70], which is a quantity used to develop modern bottom-up coarse grained model $[9,12]$.

It is important to emphasize that the use of saturated liquid viscosity in the parameterization is a crucial point of this work, as equilibrium properties can be insufficient to uniquely define a set of MCCG parameters. Indeed, it is possible to obtain two (at least) different sets of $(\varepsilon, \sigma, N, \lambda)$ which yields superposing (i.e. within uncertainties) saturated density, vapor pressure and surface tensions of a target species, as shown for the case of propane in Figs. 1a-1c. This leads to a non-uniqueness of parameters for a target species if only equilibrium properties, such as $T_{c}, \rho_{\text {sat,l }}$ and $\omega$, are considered in the top-down strategy. As shown in Fig. 1d, for the specific case of propane, this indetermination is straightforwardly removed by taking the saturated liquid viscosity into account in the parameterization of the MCCG model. Interestingly, this indetermination cannot be easily removed using second derivative thermodynamic properties of liquid on the phase equilibrium curve (isothermal compressibility, heat capacity and thermal expansion), see Figs. 1e-1g. The only exception is the saturated liquid sound velocity which seems to be discriminative between two set of parameters, see fig $1 \mathrm{~h}$, even if the discrimination is not as obvious as when using viscosity, 
see Fig. 1d. Such finding regarding sound velocity is consistent with what noticed when using an equation of state describing the Mie Chain model (SAFT VR-Mie) [27]. In addition, it is interesting to notice that when the appropriate MCCG model is used to represent propane (i.e. the dimer) all thermophysical properties are really well described, see Fig. 1.

\section{Thermophysical properties of the Coarse Grained model}

The proposed strategy requires the knowledge of the values of $\left(T_{c}^{*}, \rho_{s a t, l}^{*}, \omega, \mu^{r}\right)$ of the Mie Chain Coarse Grained model. For that purpose, we have first performed extensive Monte Carlo simulations of the saturated density and the vapor pressure of various MCCG models with $N$ varying from 1 to 8 and $\lambda$ varying from 8 to 36. As shown in Fig. 2 our simulation data are in excellent agreement with recent literature data [71-72]. Then, these data have been used to determine the critical point location, including $T_{c}^{*}$, of the Mie chain model following the procedure described in Sect. II.2. This allowed us to define the thermodynamic conditions to perform Monte Carlo simulations to determine of $\rho_{\text {sat }, l}^{*}$ and $\omega$, and to carry out Molecular Dynamics simulations to compute $\mu^{r}$. All results are provided in Fig. 3.

As expected, the acentric factor is mainly affected by the chain length whereas the reference viscosity is mainly affected by the repulsion exponent. Furthermore, Figure 3 indicates that both $\omega$ and $\mu^{r}$ increases monotonously with $N$ and $\lambda$. These features are important as they ensure that a couple of $\omega$ and $\mu^{r}$ will define a unique set of $N$ and $\lambda$.

Based on these molecular simulation results, we have developed correlations between $\left(T_{c}^{*}, \rho_{s a t, l}^{*}, \omega, \mu^{r}\right)$ and $(N, \lambda)$. As found by Mejia et al., [36], it has been noticed that these correlations are more easily expressed as function of $(N, \alpha)$ than as function of $(N, \lambda)$, where $\alpha$ is the van der Waals constant, defined as [73]: 


$$
\alpha=\int_{\sigma}^{\infty} u_{M i e} r^{2} d r=\left(\frac{\lambda}{\lambda-6}\right)\left(\frac{\lambda}{6}\right)^{6 /(\lambda-6)}\left[\left(\frac{1}{3}\right)-\left(\frac{1}{\lambda-3}\right)\right]
$$

In this set of variables, the proposed correlations allowing to determine $\left(T_{c}^{*}, \rho_{s a t, l}^{*}, \omega, \mu^{r}\right)$ of the MCCG model are the following:

$$
\begin{aligned}
& T_{c}^{*}=\left(A_{0} e^{A_{1} \sqrt{N}}+A_{2}\right) \alpha^{\left(A_{3} e^{A_{4} N}+A_{5}\right)}+\left(A_{6} e^{A_{7} / \sqrt{N}}+A_{8}\right) \\
& \rho_{\text {sat }, l}^{*}=\left(\frac{1}{N}\right)\left[\left(B_{0} \mathrm{e}^{B_{1} N}+B_{2}\right) \mathrm{e}^{\left(B_{3} \mathrm{e}^{B_{4} N}+B_{5}\right) \alpha^{1.75}}+\left(B_{6} \mathrm{e}^{B_{7} N}+B_{8}\right)\right] \\
& \omega=\left(C_{0} \sqrt{N}+C_{1}\right) \ln \left(\alpha-\alpha_{\infty}\right)+\left(C_{2} \sqrt{N}+C_{3}\right) \\
& \mu^{r}=\left(D_{0} \alpha^{D_{1}}+D_{2}\right)\left[\left(D_{3} \mathrm{e}^{D_{4} N}+D_{5}\right)\left(\alpha-\alpha_{\infty}\right)^{D_{6}}+\left(D_{7} N+D_{8}\right)\right]
\end{aligned}
$$

where $A_{i}, B_{i}, C_{i}$ and $D_{i}$ are numerical parameters, provided in Tab. 1, which have been adjusted on our molecular simulation data. $\alpha_{\infty}$, which is equal to $1 / 3$, is the vdW constant when $\lambda \rightarrow \infty$, i.e. for a Sutherland potential. The fitting has been performed so as to minimize the Absolute Average Deviation (AAD) between the results of Eqs. (10-11) and Eq. (13) and the simulation data. The minimization on the acentric factor, Eq. (12), has been carried out on the quantity $\omega+1$ to avoid the singularities when $\omega \rightarrow 0$. As shown in Fig. 3, these correlations describe very well the simulation results.

It is interesting to note that the correlations provided by Mejia et al. [36] to describe $\left(T_{c}^{*}, \rho_{s a t, l}^{*}, \omega\right)$ are consistent with our molecular simulation results, see Fig. 3. However, these correlations exhibit non-negligible differences compared with direct molecular simulation results in particular for the longest chains and for the highest repulsive exponent. This is because their correlations have been developed using data coming from an equation of state, the SAFT- $\gamma$, which, despite its good accuracy, does not perfectly represent the equilibrium data of the Mie chain fluids provided by molecular simulations. 


\section{Parameterization of the Coarse Grained model}

The proposed MCCG parameterization strategy requires the knowledge of $\left(T_{c}, \rho_{\text {sat }, l}, \omega, \mu^{r}\right)$ of the compounds of interest. $T_{c}, \omega$ and, to a less extent, $\rho_{\text {sat }, l}, \mu^{r}$ are available from experiments or from correlations in the literature for a wide range of compounds $[1,3,56,74-75]$. However, if the critical temperature is too high, e.g. long nalkanes, or if the temperature of the triple point is higher than $0.7 T_{c}$, e.g. $\mathrm{CO}_{2}, \rho_{\text {sat, } l}$ and $\mu^{r}$ are usually not available. For such species, we suggest the following procedure. For $\rho_{\text {sat,l}}$, good results will be obtained by using an extrapolation of the liquid density data along the equilibrium line based on the Guggenheim scaling [76], i.e. using the fact that $\rho_{l} \propto$ $\left(1-T_{r}\right)^{1 / 3}$. Similarly, for $\mu^{r}$, reasonable estimate will be obtained using an extrapolation of the liquid viscosity data along the equilibrium line based on the thermodynamic scaling [24], i.e. assuming that the reduced liquid viscosity on the vapor-liquid equilibrium line is proportional to $\frac{\rho_{l}^{\gamma}}{T}$ where $\gamma$ is a parameter fitted on the available data.

Once $\left(T_{c}, \rho_{s a t, l}, \omega, \mu^{r}\right)$ of the compounds of interest is known, the first step of the parameterization of the Mie Chain Coarse Grained model consists in finding $(N, \lambda)$ so as its acentric factor, $\omega_{C G}$, and its reference viscosity, $\mu_{C G}^{r}$, are as close as possible to those of the target species. This can be achieved by minimizing the following objective function, while keeping $N$ as an integer:

$$
F=\left|\frac{\omega-\omega_{C G}}{\omega+1}\right|+\left|\frac{\mu^{r}-\mu_{C G}^{r}}{\mu^{r}}\right|
$$

where $\omega_{C G}$ and $\mu_{C G}^{r}$ are obtained from equations (12) and (13), respectively.

In a second step, $(\varepsilon, \sigma)$ of the MCCG model are straightforwardly deduced from $\left(T_{c}, \rho_{\text {sat }, l}\right)$ of the target species by using the corresponding states framework $[41,60]$, i.e.: 


$$
\begin{gathered}
\varepsilon=\frac{k_{B} T_{C}}{T_{c}^{*}} \\
\sigma=\sqrt[3]{\frac{M \rho_{s a t, l}^{*}}{\rho_{\text {sat }, l}}}
\end{gathered}
$$

where $T_{c}^{*}$ and $\rho_{s a t, l}^{*}$ are obtained from Eqs. (10) and (11), respectively. Values of $\left(T_{c}, \rho_{s a t, l}, \omega, \mu^{r}\right)$ for the compounds studied in this work are provided in Tab. 2, and the corresponding results of this MCCG parameterization are presented in Tab. 3.

For sake of clarity a flowchart of the whole parameterization procedure is provided in Fig. 4. An excel sheet to apply this parameterization procedure is available on demand. It should be noticed that the proposed strategy could be used to parameterize any four (or less) parameters Coarse Grained model.

\section{Results and discussions}

\section{Pure fluids}

a. Simple fluids

As a first test we have applied the proposed coarse grained parameterization strategy on three simple compounds: Argon, Nitrogen and Methane. As expected, these compounds are represented by a single sphere with the proposed MCCG model, see Tab. 3, which confirms the consistency of the approach. Then, simulations of these MCCG models have been performed along the vapor-equilibrium curve to compute their densities, pressures and liquid viscosities. As indicated previously, surface tensions have been deduced from the universal relation provided by Galliero [53] which accurately describe the Mie chain model surface tensions [53-54]. 
Results provided in Fig. 5 clearly indicate that the proposed MCCG model is able to provide excellent predictions on all thermophysical properties, including liquid viscosity along the vapor-liquid equilibrium line. The interest of including a transport property in the parameterization is emphasized by the results obtained using some recent Mie models developed for such fluids $[15,48]$, see Fig. 5 . These models, which are built on equilibrium properties only, are good to deal with equilibrium properties, but are quite off regarding saturated liquid viscosities (except for Argon), see Fig. 5. Furthermore, even fine grained models are not always really accurate to describe transport properties, see for instance Aimoli et al. [77] regarding $\mathrm{CH}_{4}$. It is interesting to notice as well that the predicted critical point location for the simple fluids is perfectly consistent with the experimental data, see Tab. 4.

The proposed coarse grained model is, by its parameterization procedure, built to describe the vapor-liquid equilibrium region. It is so interesting to verify that it remains consistent in other thermodynamic conditions such as supercritical ones. Thus, along one isotherm at $373 \mathrm{~K}$, we have computed the densities and viscosities of the MCCG models representing $\mathrm{Ar}, \mathrm{N}_{2}$ and $\mathrm{CH}_{4}$ for various pressures from 50 to $100 \mathrm{MPa}$. As shown in Fig. 6, even far from the vapor-equilibrium region, predicted densities and viscosities are in good agreement with those of the NIST database [56], even if the viscosities of methane and nitrogen are slightly overestimated (of about $5 \%$ ).

\section{b. Normal alkanes}

As a second test, we have applied the proposed strategy to some normal alkanes: Ethane $\left(\mathrm{C}_{2}\right)$, n-Butane $\left(\mathrm{nC}_{4}\right)$, $\mathrm{n}$-Hexane $\left(\mathrm{nC}_{6}\right)$ and $\mathrm{n}$-Decane $\left(\mathrm{nC}_{10}\right)$. These are still simple fluids [78], but their corresponding MCCG model is no longer described by a single sphere, but by dimers $\left(\mathrm{C}_{2}, \mathrm{nC}_{4}\right)$, trimer $\left(\mathrm{nC}_{6}\right)$ and quadrimer $\left(\mathrm{nC}_{10}\right)$, see Tab. 3. Densities, pressures, 
surface tensions and liquid viscosities of the proposed MCCG models for these n-alkanes have been computed at the vapor-liquid equilibrium.

As shown in Fig. 7, predicted thermophysical properties of n-alkane using the MCCG models are in very good agreement with the NIST database [56]. Similarly, to what obtained in the previous section, the use of viscosity in the parameterization ensures the robustness of the results. This is pointed out by the results of the Mejia et al.'s approach [36], based on equilibrium properties only, which provides good result on static properties (saturated density, vapor pressure, surface tension) but noticeably overestimates saturated liquid viscosities for Ethane and n-Hexane, see Fig. 7.

Concerning the critical point predictions, see Tab. 4, the MCCG model yields excellent results on the critical temperature, very good results on critical density and good results on critical pressure. It appears that the MCCG model tends to slightly overestimate the critical pressure with an overestimation that increases with the chain length (up to $7.4 \%$ for $n$ decane).

In addition, we have computed the densities and viscosities of the MCCG models representing $\mathrm{C}_{2}, \mathrm{nC}_{4}, \mathrm{nC}_{6}$ and $\mathrm{nC}_{10}$ for various pressures up to $100 \mathrm{MPa}$ along one isotherm at $373 \mathrm{~K}$, see Fig. 8. The MCCG model predicts very well densities for all tested normal alkanes. The predicted viscosities are in good agreement with the NIST database for $\mathrm{C}_{2}$ and $\mathrm{nC}_{4}$, but are noticeably underestimated for $\mathrm{nC}_{6}$ and $\mathrm{nC}_{10}$ (with deviations equal to $12 \%$ and $18 \%$ at the highest pressure respectively). This limitation is probably due to the fully flexible nature of the chosen MCCG model, i.e. the lack of intra-molecular potential in the MCCG model $[38,68]$. Nevertheless, the results are still really good regarding the simplicity of the MCCG model and they compare favorably with what is usually obtained regarding viscosity prediction using fine grained models $[66,79]$. 


\section{c. Polar compounds}

As a last test on pure fluids, we have performed simulations of the MCCG model representing Hydrogen Sulfide, Carbon Dioxide and Toluene, see Tab. 2 for their parameters. Densities, pressures, surface tensions and liquid viscosities of these three species have been computed at the vapor-liquid equilibrium.

Interestingly, the MCCG model results are really consistent with experiments $[56,80$ 82] for all thermophysical property studied in this work, see Fig 9, even if the polar interactions are not introduced explicitly. Such a statement holds as well when looking at the predictions of the critical point location, see Tab. 4. Similarly to what found previously, the results obtained with the MCCG model using our parameterization strategy compares favorably with other approaches of the literature $[15,72]$, in particular when looking at liquid viscosities, see Fig. 9. However, one can notice that the saturated liquid viscosity of Toluene is systematically underestimated at the lowest temperature $(12 \%$ of deviations at $T=317 \mathrm{~K})$. As previously discussed for n-Hexane and n-Decane, this probably reflects the lack of rigidity of the proposed MCCG model (a flexible trimer in this case) compared to the real molecule.

All these results on pure fluids confirm the robustness of the proposed strategy to parameterize a simple MCCG model dedicated to describe simultaneously equilibrium and transport properties of fluids over a wide range of thermodynamics conditions. However, it should be noticed that the direct application of this methodology to strongly associating compounds (such as alcohols ...) should be taken with care in particular regarding surface tension predictions [53] and when dealing with a large range of temperature. 


\section{Binary mixtures}

\section{a. Vapor-liquid equilibria of simple binary mixtures}

One of the main question regarding force fields development, in particular when dealing with coarse grained ones, is their ability to deal with mixtures without additional fitted parameters $[7,15]$. As a first test, we have applied the proposed MCCG model to compute vapor-liquid equilibria of three binary mixtures of simple fluids: argon + krypton, krypton + xenon, xenon + methane. Figure 10 shows the results on the pressure-composition diagrams of these three binary mixtures [83-85].

Results indicate that the MCCG model is able to calculate good vapor-liquid equilibria of binary mixtures in comparison with experiments. This is consistent with recent results on the Mie Chain models based on equation of states $[29,86]$ and on simulations $[15,46,87]$ which indicate that equilibrium and interfacial properties of such mixtures are usually well described using simple combining rules such as those used in this work, i.e. Eqs. (3-5).

\section{b. Density and viscosity}

As a further test of the proposed MCCG model to predict thermophysical properties of mixtures, we have performed molecular dynamics simulations to estimate the densities and viscosities of three binary n-alkanes mixtures: $\mathrm{CH}_{4}+\mathrm{nC}_{4}$ at $377.59 \mathrm{~K}, \mathrm{CH}_{4}+\mathrm{nC}_{10}$ and $\mathrm{CH}_{4}+$ Toluene at $T=373 \mathrm{~K}$, for various pressure up to $100 \mathrm{MPa}$.

Figure 11 shows that the simulations results are reasonable when compared to experiments [56, 88-90]. More precisely, the densities are very well predicted for all mixtures even for the most asymmetric mixture, with deviations similar to those on pure fluids. Viscosity predictions are excellent for the $\mathrm{CH}_{4}+\mathrm{nC}_{4}$ mixtures, but exhibit non negligible 
underestimation for the two other mixtures for which the deviations relatively to experiments reach $18 \%$ at most. This underestimation is consistent with what noticed on pure Toluene and pure n-decane, see Sects. IV.1.b and IV.1.c respectively. Overall, the results on these three mixtures are as good as those obtained on pure fluids without additional parameter even when dealing with asymmetric mixtures such as $\mathrm{CH}_{4}+\mathrm{nC}_{10}$.

\section{c. Thermodiffusion}

The last test of the proposed MCCG model concerns its ability to predict the Soret coefficient in mixtures. This quantity associated to a phenomenon, named thermodiffusion or thermophoresis, which couples heat and mass transfer and so leads to a composition gradient when a thermal gradient is applied on a mixture [91]. In a binary mixture the Soret coefficient is defined as:

$$
S_{T}=\frac{D_{T}}{D_{12}}=-\frac{1}{x_{i}\left(1-x_{i}\right)} \frac{\nabla x_{i}}{\nabla T}
$$

where $D_{T}$ is the thermal diffusion coefficient, $D_{12}$ is the mutual diffusion coefficient and $x_{i}$ is the molar fraction of component $i$.

This cross-transport property is still relatively difficult to measure experimentally and there is a lack of a general model to quantify it in dense state despite recent major improvements [91-92]. The Soret coefficient is known to be very sensitive to the force field, in particular regarding cross-interactions description [93-96]. It is so a significant test for any force field aiming at describing mixtures. As a first example, we have performed simulations of the thermodiffusion of Ar-Kr liquid mixtures, i.e. simple spherical molecules, for which experimental data and molecular simulations are already available in the literature [97-98]. Then, as a second example, simulations have been performed on the more complex $\mathrm{nC}_{5}-\mathrm{nC}_{10}$ 
mixture at ambient conditions for which experimental data and molecular simulations of a fine grained model are available [99]. Results are provided in Tab. 5.

Very interestingly the results show that the MCCG model yields reasonable predictions of the Soret coefficients of the studied mixtures. More precisely, simulation results are consistent with experiments for the $\mathrm{Ar}-\mathrm{Kr}$ mixtures and show a systematic underestimation of the Soret coefficient (between $10 \%$ and $30 \%$ depending on the concentration) for the $\mathrm{nC}_{5}-\mathrm{nC}_{10}$ mixtures. This discrepancy on the $\mathrm{nC}_{5}-\mathrm{nC}_{10}$ mixture results is similar to what obtained using a fine grained model [99], see Tab. 5.

All these results confirm the consistency of the proposed MCCG model to deal with the studied mixtures without any additional parameters, which reinforces the interest of the proposed strategy. However, it should be noticed that the usability of the LB combining rules without extra parameters may be a consequence of the nature of the particular mixtures (not highly asymmetric in size) studied in this work.

\section{Conclusions}

In this work, we have developed a robust top-down strategy to parameterize state independent coarse grained force fields based on the four parameters Mie Chain model. The so-defined Mie Chain Coarse Grained model combined with molecular simulations is able to provide simultaneously equilibrium and transport thermophysical properties of nonassociating compounds in various fluid states. The proposed MCCG model parameterization strategy relies on an extended corresponding states approach similar to that proposed by Mejia et al. [36]. However, our approach is based on extensive molecular simulations data instead of an equation of state as in Mejia et al. [36] and, more important, the procedure has been complemented by the integration of a reference shear viscosity to parameterize univocally the 
MCCG force fields. This parameterization requires so four macroscopic quantities for a given target compounds, the critical temperature, one saturated liquid density, the acentric factor and one saturated liquid viscosity.

Molecular simulations (Monte Carlo and Molecular Dynamics) of the so-developed MCCG model representing various pure fluids (n-alkanes, $\mathrm{CO}_{2} \ldots$ ) has been performed along the vapor-liquid equilibrium curve. Simulation results have shown that critical points, saturated densities, vapor pressures and surface tensions of these pure fluids are very well predicted by the MCCG model. Interestingly, it has been found that predicted saturated liquid viscosities are as well consistent with experiments, which is an improvement over previous similar coarse grained models which are using only equilibrium properties for their parameterization. However, a systematic slight underestimation of the saturated liquid viscosity of the largest studied molecules at the lowest temperatures has been noticed. This weakness is probably related to the fully flexible nature of the chosen MCCG model and will be the topic of further works. In addition, molecular simulations of density and viscosity of the studied compounds have been performed for pressure up to $100 \mathrm{MPa}$ at $T=373 \mathrm{~K}$. The results have been found as accurate as those obtained on the liquid-vapor equilibrium curve, which emphasizes the robustness of the proposed MCCG model to deal with different fluid thermodynamic conditions.

To further assess the consistency and the robustness of the proposed approach, molecular simulations of the MCCG model have been performed on various binary mixtures, including asymmetric ones (methane $+\mathrm{n}$-decane), using classical Lorentz-Berthelot combining rules. Simulation results on vapor-liquid equilibria have shown that the predicted pressure-composition phase diagrams of binary mixtures of simple fluids (noble gases and methane) are in good agreement with the experimental ones. In addition, predictions of densities and viscosities of some liquid binary mixtures of hydrocarbons for pressure up to 
$100 \mathrm{MPa}$ have been found to be as good as those obtained on pure fluids. Finally, it has been found that the proposed MCCG model is able to provide the Soret coefficients of Ar-Kr and $\mathrm{nC}_{5}-\mathrm{nC}_{10}$ mixtures with a reasonable accuracy, i.e. with an absolute deviation relatively to the experimental values of the order of $10 \%$. This is an interesting result as this transport property is known to be highly sensitive to the force field. These results on binary mixtures confirm the reliability of the proposed MCCG model to deal with mixtures without additional parameterization which reinforces the interest of the proposed strategy.

Molecular simulations of the so-developed MCCG model have been performed in this work to compute thermophysical properties of the studied systems. However, it should be pointed out, that the proposed strategy could be used as well in combination with modern theories providing some thermophysical properties. By doing so it could be possible to remove the need of molecular simulations in particular when dealing with equilibrium and interfacial properties $[27,29,53,100]$. Nevertheless, regarding transport properties further theoretical developments are required even if recent progresses have been achieved [3, 24, 61, $101]$

Acknowledgements: The authors express their sincere thanks to Dr. J. Bickert and Dr. F. Montel from TOTAL EP for the stimulating discussions. We gratefully acknowledge TOTAL S.A. for the post-doctoral grant awarded to one of us $(\mathrm{HH})$ and for letting us publish these results. We would like to thank ESA for a partial support to this work and Scienomics for our participation to the Scienomics' Group of Scientific Excellence. We also thank the Pau University and the MCIA for providing computational facilities. 


\section{References}

[1] Poling, B. E.; Prausnitz, M.; O’Connell, J. P. The Properties of Gases and Liquids; Fifth Edition, McGraw-Hill, 2004.

[2] Goodwin, A. R.; Sengers, J.; Peters, C. J. Applied Thermodynamics of Fluids; Royal Society of Chemistry, 2010.

[3] Assael, M. J.; Goodwin, A. R. H.; Vesovic, V.; Wakeham, W. A. Experimental Thermodynamics Volume IX: Advances in Transport Properties of Fluids; Royal Society of Chemistry: London, 2014.

[4] Allen, M. P.; Tildesley, D. J. Computer Simulations of Liquids; Oxford University Press: New York, 1987.

[5] Frenkel, D.; Smit, B. Understanding Molecular Simulation: From Algorithms to Applications; Second Edition, Academic Press, 2001.

[6] Hansen, J. P.; McDonald, I. R. Theory of Simple Liquids; Fourth Edition, Academic Press: Oxford, 2013.

[7] Ungerer, P.; Tavitian, B.; Boutin, A. Applications of Molecular Simulation in the Oil and Gas Industry; Technip, 2005.

[8] Müller-Plathe, F. Coarse-Graining in Polymer Simulation: From the Atomistic to the Mesoscopic Scale and Back. ChemPhysChem 2002, 3, 754.

[9] Shell, M. S. The relative entropy is fundamental to multiscale and inverse thermodynamic problems. J. Chem. Phys. 2008, 129, 144108.

[10] Guevara-Carrion, G.; Hasse, H.; Vrabec, J. Thermodynamic Properties for Applications in Chemical Industry via Classical Force Fields. Top. Curr. Chem. 2012, 307, 201. 
[11] Brini, E.; Algaer, E. A.; Ganguly, P.; Li, C.; Rodríguez-Ropero, F.; van der Vegt, N. F. A. Systematic coarse-graining methods for soft matter simulations - a review. Soft Matter 2013. 9, 2108.

[12] Noid, W. G. Perspective: Coarse-grained models for biomolecular systems. J. Chem. Phys. 2013, 139, 090901.

[13] Marrink, S. J.; Tielemanb, D. P. Perspective on the Martini model. Chem. Soc. Rev. 2013, 42, 6801 .

[14] Goga, N.; Melo, M. N; Rzepiela, A. J.; de Vries, A. H.; Hadar, A.; Marrink, S. J.; Berendsen, H. J. C. Benchmark of Schemes for Multiscale Molecular Dynamics Simulations. J. Chem. Theory Comput. 2015, 11, 1389.

[15] Herdes, C.; Totton, T. S.; Müller, E. A. Coarse grained force field for the molecular simulation of natural gases and condensates. Fluid Phase Equilib. 2015, 406, 91.

[16] Wang, P.; Li, Z.; Ma, Y.; Sun, X.; Liu, Z.; Zhang, J. The coarse-grained model for a water/oil/solid system: Based on the correlation of water/air and water/oil contact angles. $R S C$ Advances 2015, 5, 51135.

[17] Jover, J. F.; Müller, E. A.; Haslam, A. J.; Galindo, A.; Jackson, G.; Toulhoat, H.; NietoDraghi, C. Aspects of Asphaltene Aggregation Obtained from Coarse-Grained Molecular Modeling. Energy Fuels 2015, 29, 556.

[18] Zhang, M.; Müller-Plathe, F. The Soret effect in dilute polymer solutions: Influence of chain length, chain stiffness, and solvent quality. J. Chem. Phys. 2006, 125, 124903. 
[19] Touzet, M.; Galliero, G.; Lazzeri, V.; Saghir, M. Z.; Montel, F.; Legros, J. C. Thermodiffusion: From microgravity experiments to the initial state of petroleum reservoirs. CR Mecanique 2011, 339, 318.

[20] Galliero, G.; Bataller, H.; Croccolo, F.; Vermorel, R.; Artola, P. A.; Rousseau, B.; Vesovic, V.; Bou-Ali, M.; Ortiz de Zárate, J. M.; Xu, S.; Zhang, K.; Montel, F. Impact of Thermodiffusion on the Initial Vertical Distribution of Species in Hydrocarbon Reservoirs. Microgravity Sci. Technol. 2016, 28, 79.

[21] Müller, E.; Gubbins, K. E. Molecular-Based Equations of State for Associating Fluids: A Review of SAFT and Related Approaches. Ind. Eng. Chem. Res. 2001, 40, 2193.

[22] Galliero, G.; Boned, C. Shear viscosity of the Lennard-Jones chain fluid in its gaseous, supercritical, and liquid states. Phys. Rev. E 2009, 79, 021201.

[23] Galliero, G.; Boned, C. Thermal conductivity of the Lennard-Jones chain fluid model. Phys. Rev. E 2009, 80, 061202.

[24] Galliero, G.; Boned, C.; Fernandez, J. Scaling of the viscosity of the Lennard-Jones chain fluid model, argon, and some normal alkanes. J. Chem. Phys. 2011, 134, 064505.

[25] Vaz, R. V.; Magalhães, A. L.; Fernandes, D. L. A.; Silva, C. M. Universal correlation of self-diffusion coefficients of model and real fluids based on residual entropy scaling law. Chem. Eng. Sci. 2012, 79, 153.

[26] de Wijn, A. S.; Riesco, N.; Jackson, G.; Trusler, J. P. M.; Vesovic, V. Viscosity of liquid mixtures: The Vesovic-Wakeham method for chain molecules. J. Chem. Phys. 2012, 136, 074514. 
[27] Lafitte, T.; Apostolakou, A.; Avendaño, C.; Galindo, A.; Adjiman, C. S.; Müller, E. A.; Jackson, G. Accurate statistical associating fluid theory for chain molecules formed from Mie segments. J. Chem. Phys. 2013, 139, 154504.

[28] Llovell, F.; Marcos, R. M.; Vega, L. F. Transport properties of mixtures by the softSAFT+ free-volume theory: application to mixtures of n-alkanes and hydrofluorocarbons. $J$. Phys. Chem. B 2013, 117, 5195.

[29] Garrido, J. M.; Mejia, A.; Pineiro, M. M.; Blas, F. J.; Müller, E. A. Interfacial tensions of industrial fluids from a molecular-based square gradient theory. AIChe J. 2016, 62, 1781.

[30] Maerzke, K. A.; Siepmann, J. I. Transferable Potentials for Phase Equilibria-CoarseGrain Description for Linear Alkanes. J. Phys. Chem. B 2011, 115, 3452.

[31] Trément, S.; Schnell, B.; Petitjean, L.; Couty, M.; Rousseau, B. Conservative and dissipative force field for simulation of coarse-grained alkane molecules: A bottom-up approach. J. Chem. Phys. 2014, 140, 134113.

[32] Moore, T. C.; Iacovella, C. R.; McCabe, C. Derivation of coarse-grained potentials via multistate iterative Boltzmann inversion. J. Chem. Phys. 2014, 140, 224104.

[33] Sanyal, T.; Shell, M. S. Coarse-grained models using local-density potentials optimized with the relative entropy: Application to implicit solvation. J. Chem. Phys. 2016, 145, 034109.

[34] Dunn, N. J. H.; Noid, W. G. Bottom-up coarse-grained models with predictive accuracy and transferability for both structural and thermodynamic properties of heptane-toluene mixtures. J. Chem. Phys. 2016, 144, 204124. 
[35] van Westen, T.; Vlugt, T. J. H.; Gross, J. Determining Force Field Parameters Using a Physically Based Equation of State. J. Phys. Chem. B 2011, 115, 7872.

[36] Mejia, A.; Herdes, C.; Müller, E. A. Force Fields for Coarse-Grained Molecular Simulations from a Corresponding States Correlation. Ind. Eng. Chem. Res. 2014, 53, 4131.

[37] Müller, E. A.; Jackson, G. Force-Field Parameters from the SAFT- $\gamma$ Equation of State for Use in Coarse-Grained Molecular Simulations. Annu. Rev. Chem. Biomol. Eng. 2014, 5, 405.

[38] Galliero, G. Equilibrium, interfacial and transport properties of n-alkanes: Towards the simplest coarse grained molecular model. Chem. Eng. Res. Des. 2014, 92, 3031.

[39] Vrabec, J.; Huang, Y. L.; Hasse, H. Molecular models for 267 binary mixtures validated by vapor-liquid equilibria: A systematic approach. Fluid Phase Equilib. 2009, 279, 120.

[40] Avendaño, C.; Lafitte, T.; Galindo, A.; Adjiman, C. S.; Jackson, G.; Müller, E. A. SAFT$\gamma$ Force Field for the Simulation of Molecular Fluids. 1. A Single-Site Coarse Grained Model of Carbon Dioxide. J. Phys. Chem. B 2011, 115, 11154.

[41] Xiang, H. W. The corresponding states Principle and its practice; Elsevier, 2005.

[42] Galliero, G.; Boned, C.; Baylaucq, A.; Montel, F. High-Pressure Acid-Gas Viscosity Correlation. SPE J. 2010, 15, 682.

[43] Platten, F.; Valadez-Pérez, N. E.; Castañeda-Priego, R.; Egelhaaf, S. U. Extended law of corresponding states for protein solutions. J. Chem. Phys. 2015, 142, 174905.

[44] Ervik, A.; Mejia, A.; Müller, E. A. Bottled SAFT: A Web App Providing SAFT- $\gamma$ Mie Force Field Parameters for Thousands of Molecular Fluids. J. Chem. Inf. Model. 2016, 56, 1609.

[45] Mie, G. Zur kinetischen Theorie der einatomigen Körper. Annu. Phys. 1903, 316, 657. 
[46] Schnabel, T.; Vrabec, J.; Hasse, H. Unlike Lennard-Jones parameters for vapor-liquid equilibria. J. Mol. Liq. 2007, 135, 170.

[47] Haslam, A. J.; Galindo, A.; Jackson, G. Prediction of binary intermolecular potential parameters for use in modelling fluid mixtures. Fluid Phase Equilib. 2008, 266, 105.

[48] Mick, J. R.; Barhaghi, M. S.; Jackman, B.; Rushaidat, K.; Schwiebert, L.; Potoff, J. J. Optimized Mie potentials for phase equilibria: Application to noble gases and their mixtures with n-alkanes. J. Chem. Phys. 2015, 143, 114504.

[49] Panagiotopoulos, A. Z. Direct determination of phase coexistence properties of fluids by Monte Carlo simulation in a new ensemble. Mol. Phys. 1987, 61, 813.

[50] Panagiotopoulos, A. Z.; Quirke, N.; Stapleton, M.; Tildesley, D. J. Phase equilibria by simulation in the Gibbs ensemble: alternative derivation, generalization and application to mixture and membrane equilibria. Mol. Phys. 1988, 63, 527.

[51] Panagiotopoulos, A. Z. Monte Carlo methods for phase equilibria of fluids. J. Phys. Condens. Matter 2000, 12, R25.

[52] Okumura, H.; Yonezawa, F. Liquid-vapor coexistence curves of several interatomic model potentials. J. Chem. Phys. 2000, 113, 9162.

[53] Galliero, G. Surface tension of short flexible Lennard-Jones chains: Corresponding states behavior. J. Chem. Phys. 2010, 133, 074705.

[54] Blas, F. J.; Martinez-Ruiz, F. J.; Moreno-Ventas Bravo, A. I.; MacDowell, L. G. Universal scaling behaviour of surface tension of molecular chains. J. Chem. Phys. 2012, 137, 024702 . 
[55] Lagache, M.; Ungerer, P.; Boutin, A.; Fuchs, A. H. Prediction of thermodynamic derivative properties of fluids by Monte Carlo simulation. Phys. Chem. Chem. Phys. 2001, 3, 4333.

[56] Lemmon, E. W.; Huber, M. L.; McLinden, M. O. Reference Fluid Thermodynamic and Transport Properties, NIST Standard Reference Database 23; REFPROP Version 8.0, 2007.

[57] Müller-Plathe, F.; Reith, D. Cause and effect reversed in non-equilibrium molecular dynamics: an easy route to transport coefficients. Comput. Theor. Polymer Sci. 1999, 9, 203.

[58] Andersen, H. C. Rattle: A "velocity" version of the shake algorithm for molecular dynamics calculations. J. Comput. Phys. 1983, 52, 24.

[59] Berendsen, H. J. C.; Postma, J. P. M.; van Gunsteren, W. F.; Dinola, A.; Haak, J. R. Molecular dynamics with coupling to an external bath. J. Chem. Phys. 1984, 81, 3684.

[60] Prausnitz, J. M.; Lichtenthaler, R. N.; Gomes de Azevedo, E. Molecular Thermodynamics of Fluid-Phase Equilibria; Third Edition, Prentice Hall, 1998.

[61] Pitzer, K. S.; Lippmann, D. Z.; Curl Jr., R. F.; Huggins, C. M.; Petersen, D. E. The Volumetric and Thermodynamic Properties of Fluids. II. Compressibility Factor, Vapor Pressure and Entropy of Vaporization. J. Am. Chem. Soc. 1955, 77, 3433.

[62] Willman, B.; Teja, A. S. Characteristic viscosity as a third parameter in corresponding states calculations of transport properties: Part I. Defined mixtures. Chem. Eng. J. 1988, 37, 65.

[63] Shi, Z.; Debenedetti, P. G.; Stillinger, F. H.; Ginart, P. Structure, dynamics, and thermodynamics of a family of potentials with tunable softness. J. Chem. Phys. 2011, 135, 084513. 
[64] Bøhling, L.; Bailey, N. P.; Schrøder, T. B.; Dyre, J. C. Estimating the density-scaling exponent of a monatomic liquid from its pair potential. J. Chem. Phys. 2014, 140, 124510.

[65] Delage-Santacreu, S.; Galliero, G.; Hoang, H.; Bazile, J. P.; Boned, C.; Fernandez, J. Thermodynamic scaling of the shear viscosity of Mie n-6 fluids and their binary mixtures. $J$. Chem. Phys. 2015, 142, 174501.

[66] Dysthe, D. K.; Fuchs, A. H.; Rousseau, B. Fluid transport properties by equilibrium molecular dynamics. III. Evaluation of united atom interaction potential models for pure alkanes. J. Chem. Phys. 2000, 112, 7581.

[67] Galliero, G.; Boned, C.; Baylaucq, A.; Montel, F. Molecular dynamics comparative study of Lennard-Jones $\alpha-6$ and exponential $\alpha-6$ potentials: Application to real simple fluids (viscosity and pressure). Phys. Rev. E 2006, 73, 061201.

[68] Nieto-Draghi, C.; Ungerer, P.; Rousseau, B. Optimization of the anisotropic united atoms intermolecular potential for n-alkanes: Improvement of transport properties. J. Chem. Phys. 2006, $125,044517$.

[69] Gordon, P. A. Development of intermolecular potentials for predicting transport properties of hydrocarbons. J. Chem. Phys. 2006, 125, 014504.

[70] Rosenfeld, Y. A quasi-universal scaling law for atomic transport in simple fluids. $J$. Phys. Condens. Matter 1999, 11, 5415.

[71] MacDowell, L. G.; Blas, F. J. Surface tension of fully flexible Lennard-Jones chains: Role of long-range corrections. J. Chem. Phys. 2009, 131, 074705.

[72] Werth, S.; Stöbener, K.; Horsch, M.; Hasse, H. Simultaneous description of bulk and interfacial properties of fluids by the Mie potential. Mol. Phys. 2017, 115, 1017. 
[73] Ramrattan, N. S.; Avendano, C.; Muller, E. A.; Galindo, A. A corresponding-states framework for the description of the Mie family of intermolecular potentials. Mol. Phys. 2015, 113, 932.

[74] Yaws, C. L. Thermodynamic and Physical Property Data; Gulf Publishing Company, 1992.

[75] DECHEMA Information Systems \& Databases.

[76] Guggenheim, E. A. The Principle of Corresponding States. J. Chem. Phys. 1945, 13, 253.

[77] Aimoli, C. G.; Maginn, E. J.; Abreu, C. R. A. Transport properties of carbon dioxide and methane from molecular dynamics simulations. J. Chem. Phys. 2014, 141, 134101.

[78] Shrivastav, G.; Agarwal, M.; Chakravarty, C.; Kashyap, H. K. Thermodynamic regimes over which homologous alkane fluids can be treated as simple liquids. J. Mol. Liq. 2017, 231, 106.

[79] Payal, R. S.; Balasubramanian, S.; Rudra, I.; Tandon, K.; Mahlke, I.; Doyle, D.; Cracknell, R. Shear viscosity of linear alkanes through molecular simulations: quantitative tests for n-decane and n-hexadecane. Mol. Sim. 2012, 38, 1234.

[80] Santos, F. J. V.; Nieto de Castro, C. A.; Dymond, J. H.; Dalaouti, N. K.; Assael, M. J.; Nagashima, A. Standard Reference Data for the Viscosity of Toluene. J. Phys. Chem. Ref. Data 2006, 35, 1.

[81] Yarranton, H. W.; Satyro, M. A. Expanded Fluid-Based Viscosity Correlation for Hydrocarbons. Ind. Eng. Chem. Res. 2009, 48, 3640.

[82] Satyro, M. A.; Yarranton, H. W. Expanded fluid-based viscosity correlation for hydrocarbons using an equation of state. Fluid Phase Equilib. 2010, 298, 1. 
[83] Schouten, J. A.; Deerenberg, A.; Trappeniers, N. J. Vapour-liquid and gas-gas equilibria in simple systems: IV. The system argon-krypton. Physica 1975, 81A, 151.

[84] Calado, J. C. G.; Chang, E.; Streett; W. B., Vapour-liquid equilibrium in the kryptonxenon system. Physica 1983, 117A, 127.

[85] Dias, L. M. B.; Filipe, E. J. M.; McCabe, C.; Calado, J. C. G. Thermodynamics of Liquid (Xenon + Methane) Mixtures. J. Phys. Chem. B 2004, 108, 7377.

[86] Dufal, S.; Lafitte, T.; Galindo, A.; Jackson, G.; Haslam, A. J. Developing intermolecularpotential models for use with the SAFT-VR Mie equation of state. AIChe J. 2015, 61, 2891.

[87] Mejia, A.; Cartes, M.; Segura, H.; Müller, E. A. Use of Equations of State and Coarse Grained Simulations to Complement Experiments: Describing the Interfacial Properties of Carbon Dioxide + Decane and Carbon Dioxide + Eicosane Mixtures. J. Chem. Eng. Data 2014, 59, 2928.

[88] Carmichael, L. T.; Berry, V. M.; Sage, B. H. Viscosity of a mixture of methane and butane. J. Chem. Eng. Data 1967, 12, 44.

[89] Baylaucq, A.; Boned, C.; Canet, X.; Zéberg-Mikkelsen, C. K. High-Pressure (up to 140 MPa) Dynamic Viscosity of the Methane and Toluene System: Measurements and Comparative Study of Some Representative Models. Int. J. Thermophys. 2003, 24, 621.

[90] Canet, X.; Baylaucq, A.; Boned, C. High-Pressure (up to $140 \mathrm{MPa}$ ) Dynamic Viscosity of the Methane+Decane System. Int. J. Thermophys. 2002, 23, 1469.

[91] Wiegand, S. Thermal diffusion in liquid mixtures and polymer solutions. J. Phys. Condens. Matter 2004, 16, R357. 
[92] Köhler, W.; Morozov, K. I. The Soret Effect in Liquid Mixtures - A Review. J. NonEquilib. Thermodyn. 2016, 41, 151.

[93] Chapman, S.; Cowling, T. G. The Mathematical Theory of Non-Uniform Gases; Cambridge University Press: Cambridge, 1981.

[94] Galliero, G.; Duguay, B.; Caltagirone, J. P.; Montel, F. Thermal diffusion sensitivity to the molecular parameters of a binary equimolar mixture, a non-equilibrium molecular dynamics approach. Fluid Phase Equilib. 2003, 208, 171.

[95] Piazza, R.; Iacopini, S.; Triulzi, B. Thermophoresis as a probe of particle-solvent interactions: The case of protein solutions. Phys. Chem. Chem. Phys. 2004, 6, 1616.

[96] Artola, P. A.; Rousseau, B.; Galliero, G. A new model for thermal diffusion: kinetic approach. J. Am. Chem. Soc. 2008, 130, 10963.

[97] Longree, D.; Legros, J. C.; Thomaes, G. Measured Soret coefficients for simple liquified gas mixtures at low temperatures. J. Phys. Chem. 1980, 84, 3480.

[98] Perronace, A.; Ciccotti, G.; Leroy, F.; Fuchs, A. H.; Rousseau, B. Soret coefficient for liquid argon-krypton mixtures via equilibrium and nonequilibrium molecular dynamics: A comparison with experiments. Phys. Rev. E 2002, 66, 031201.

[99] Perronace, A.; Leppla, C.; Leroy, F.; Rousseau, B.; Wiegand, S. Soret and mass diffusion measurements and molecular dynamics simulations of n-pentane-n-decane mixtures. $J$. Chem. Phys. 2002, 116, 3718.

[100] Galliero, G.; Piñeiro, M. M.; Mendiboure, B.; Miqueu, C.; Lafitte, T.; Bessieres, D. Interfacial properties of the Mie n-6 fluid: Molecular simulations and gradient theory results. J. Chem. Phys. 2009, 130, 104704. 
[101] Lötgering-Lin, O.; Gross, J. Group Contribution Method for Viscosities Based on Entropy Scaling Using the Perturbed-Chain Polar Statistical Associating Fluid Theory. Ind. Eng. Chem. Res. 2015, 54, 7942. 
Figure 1: Thermophysical properties of two different MCCG models modeling propane. Open symbols: $N=1, \lambda=36.77, \varepsilon=3621.9 \mathrm{~J} / \mathrm{Mol}, \sigma=4.855 \AA$. Full symbol: $N=2, \lambda=13.46, \varepsilon=1875.0$ J/Mol, $\sigma=3.671 \AA \AA$. Solid lines: NIST database [56]. Star symbol: Critical point from NIST database. (a) Saturated density. (b) Vapor pressure. (c) Surface tension. (d) Saturated liquid viscosity. (e) Saturated liquid isothermal compressibility. (f) Saturated liquid thermal expansion. (g) Saturated liquid heat capacity. (h) Saturated liquid sound velocity.
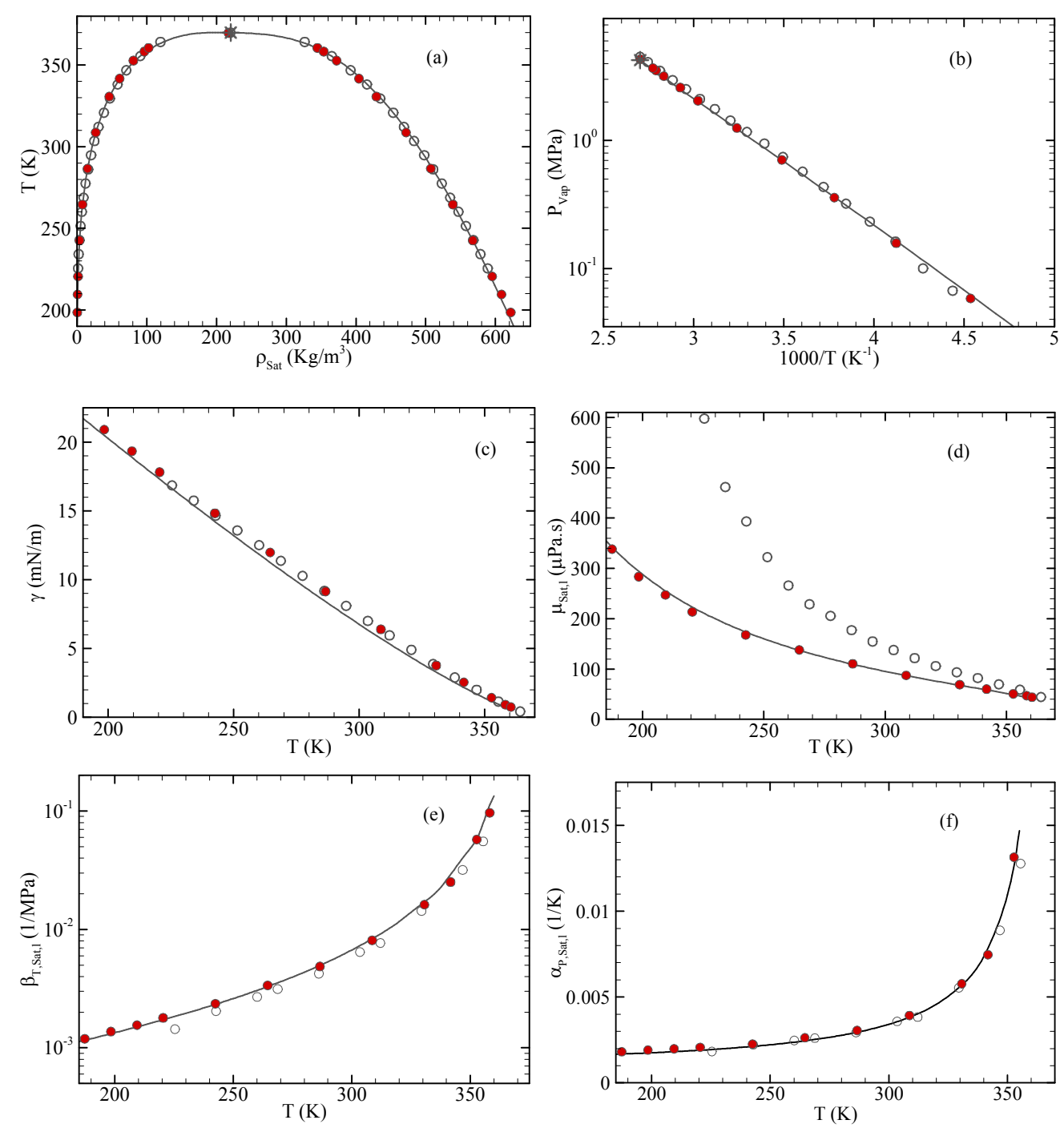

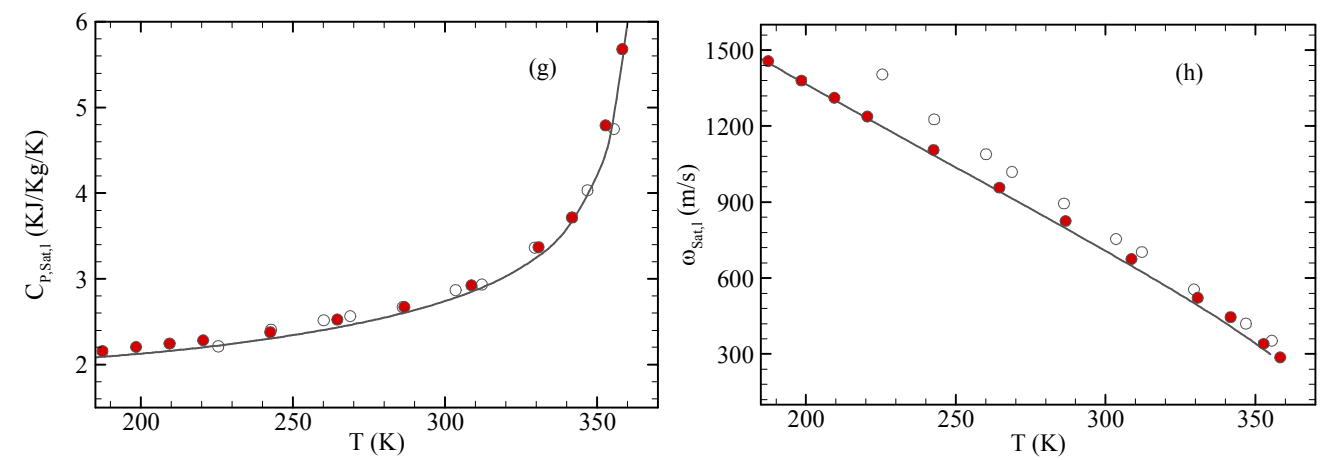

14

15

16

17

19

20

21 
Figure 2: Saturated densities (a) and (c), and vapor pressures (b) and (d) of some Mie Chains fluids obtained from this work (full symbols) and compared with literature data (open symbols) [71-72]. (a) and (b) correspond to $N=1$. (c) and (d) correspond to $\lambda=12$. Solid lines serve as a guide for the eye and are based on the results obtained in this work.
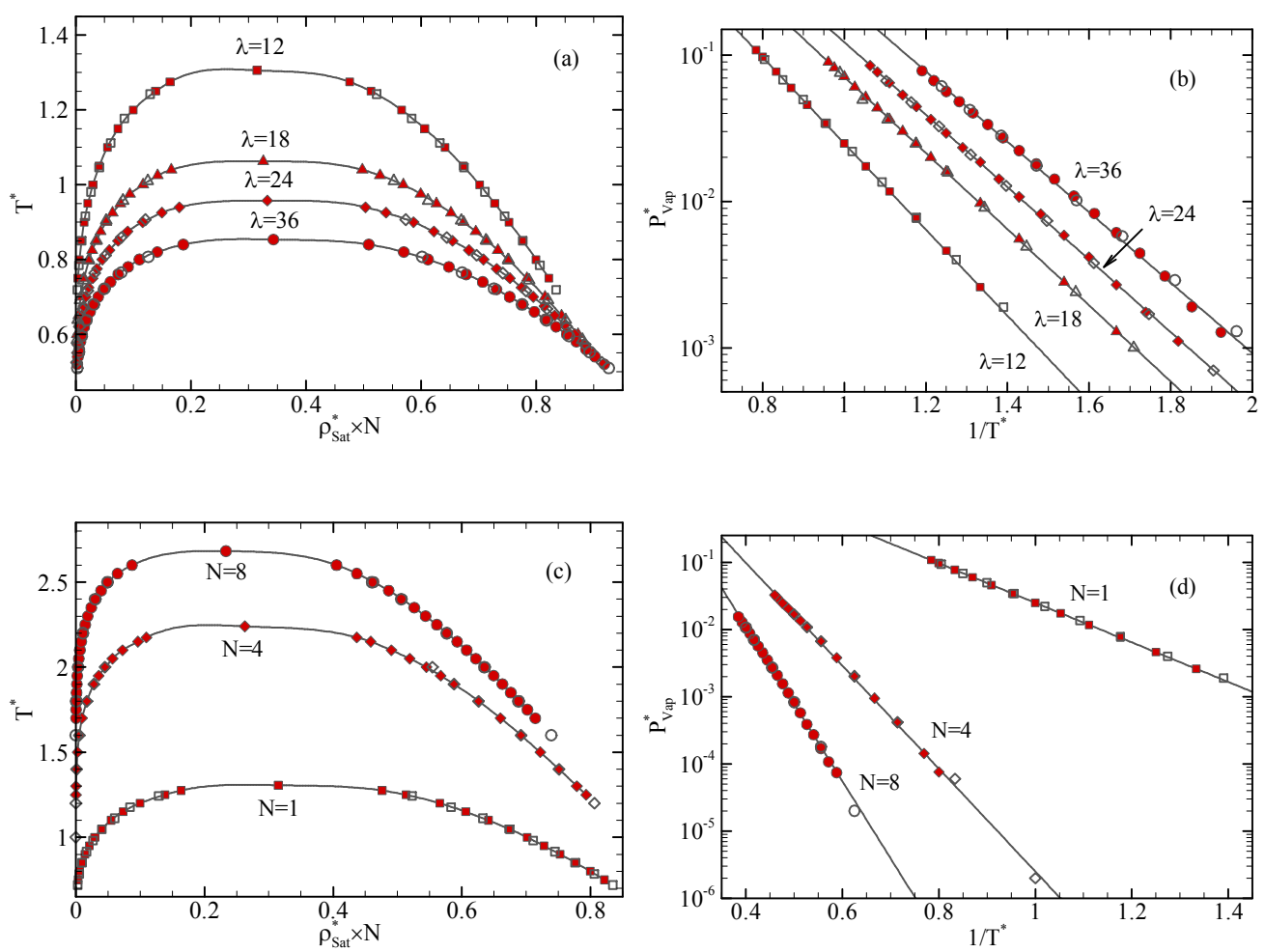

36

37

38

39

40

41

42

43

44

45

46

47

48

49

50

51

52

53

54

55

56 
Figure 3: Thermophysical properties of the MCCG model used in the parameterization procedure. (a) Critical temperature. (b) Saturated liquid density at $T_{r}=0.7$. (c) Acentric factor. (d) Reference viscosity. Symbols (square: $\lambda=8$, up triangle: $\lambda=12$, right triangle: $\lambda=18$, diamond: $\lambda=24$ and circle: $\lambda=36$ ): molecular simulations. Full lines: correlations, i.e. Eqs. (10-13). Dashed lines: correlations obtained from SAFT- $\gamma[36]$.
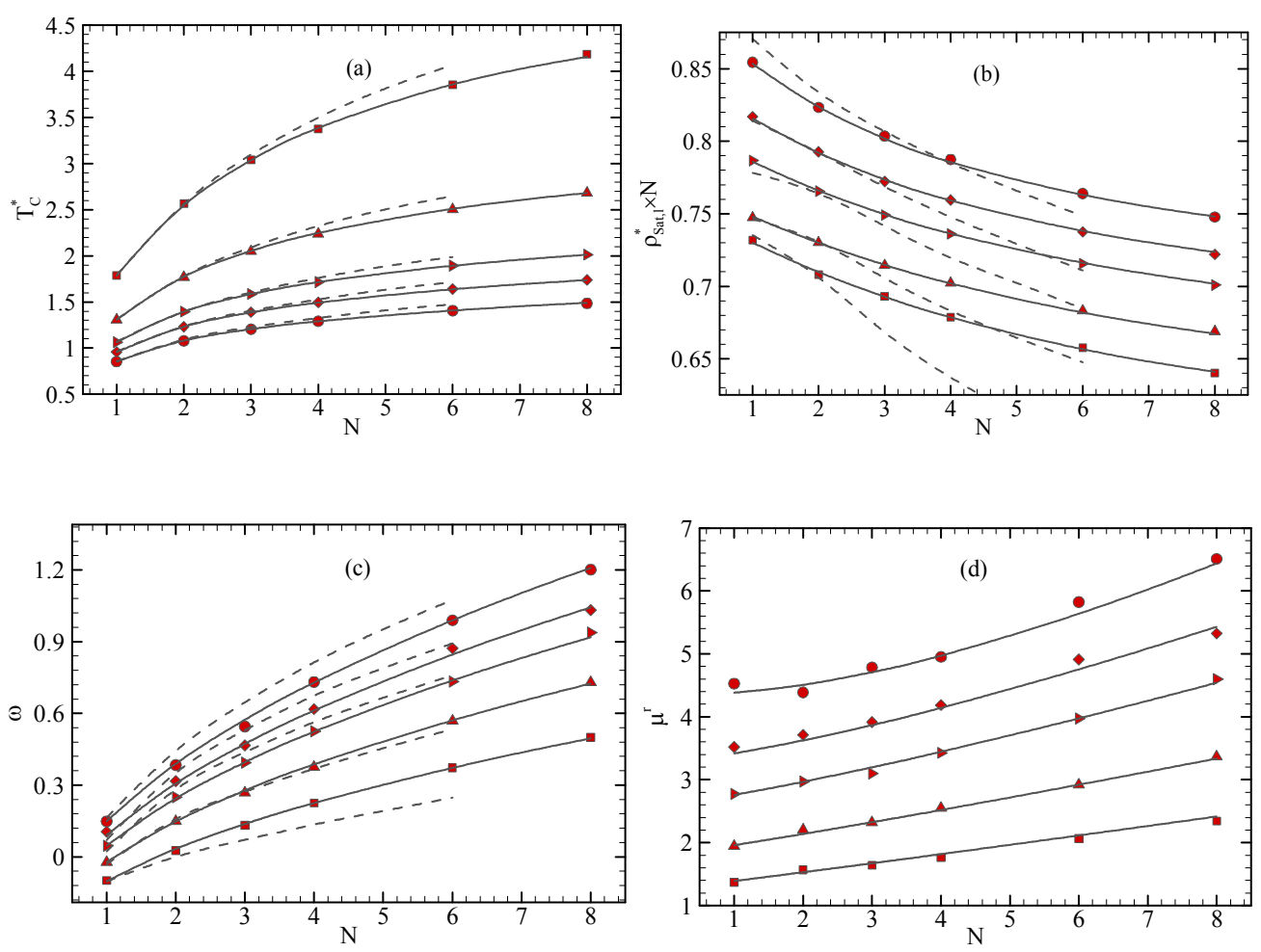

39

40

41

42

43

44

45

46

47

48

49

50

51

52

53

54

55

56 
Figure 4: Flowchart of the parameterization procedure

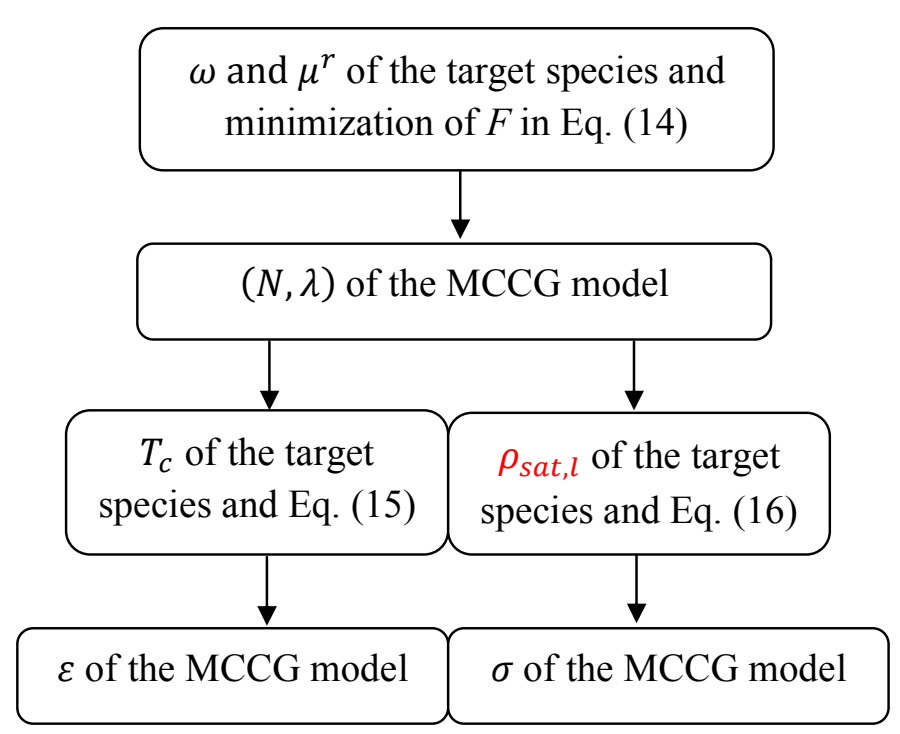


Figure 5: Thermophysical properties of Argon, Nitrogen and Methane at the vapor-liquid equilibrium. (a) Saturated density. (b) Vapor pressure. (c) Surface tension. (d) Saturated liquid viscosity. Filled circle: our MCCG model, open squares: Mick et al. [48] model, open triangles: usual Lennard-Jones [67] model. Open diamonds: Herdes et al. [15]., solid lines: NIST Database [56]. For clarification, symbols and lines associated with Ar in Fig. (d) have been shifted to the right by $40^{\circ} \mathrm{C}$.
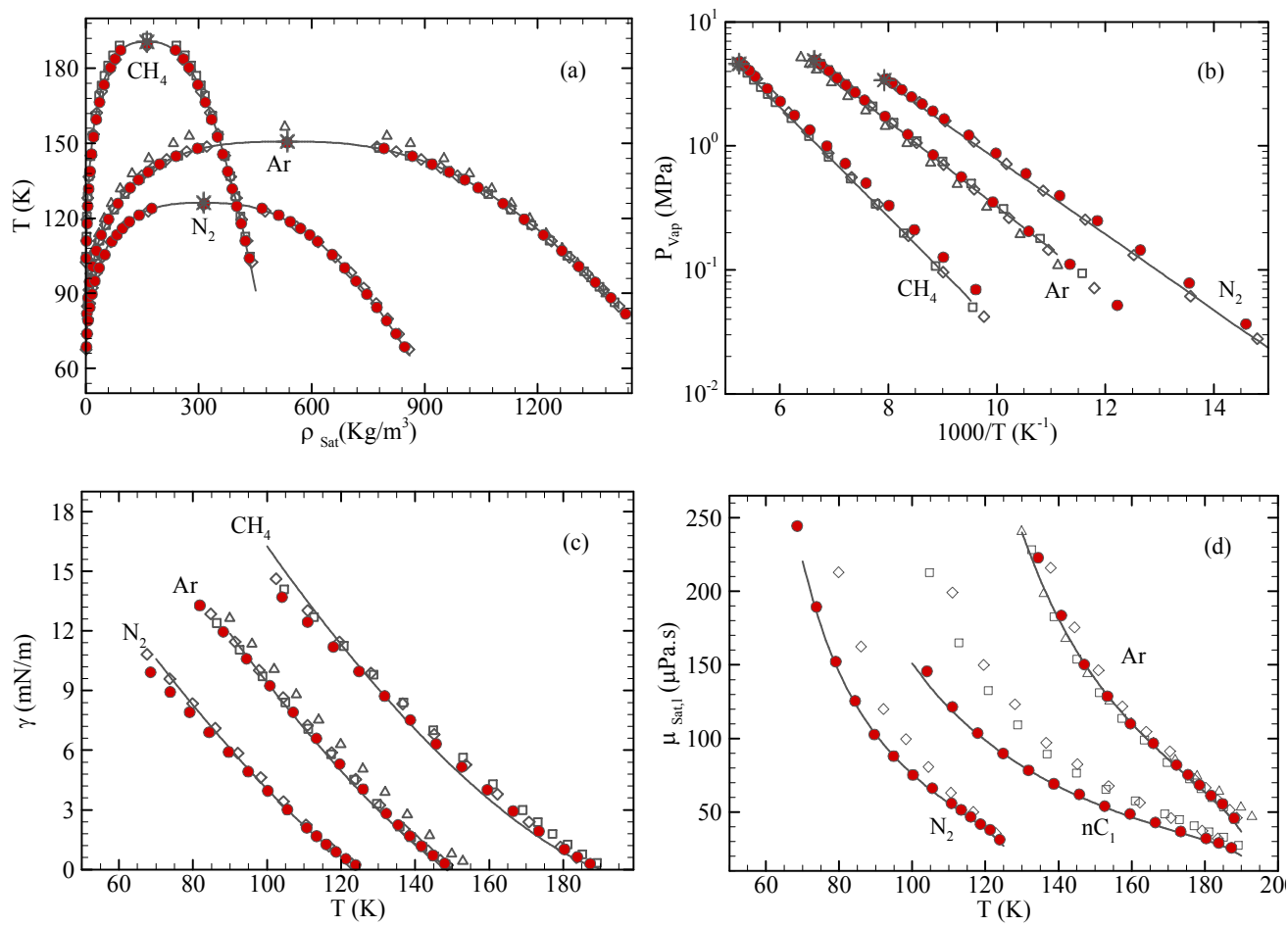
Figure 6: Density (left figure) and viscosity (right figure) of $\mathrm{Ar}, \mathrm{CH}_{4}$ and $\mathrm{N}_{2}$ for various pressures at T=373K. Symbols: MCCG model; Solid lines: NIST database [56].
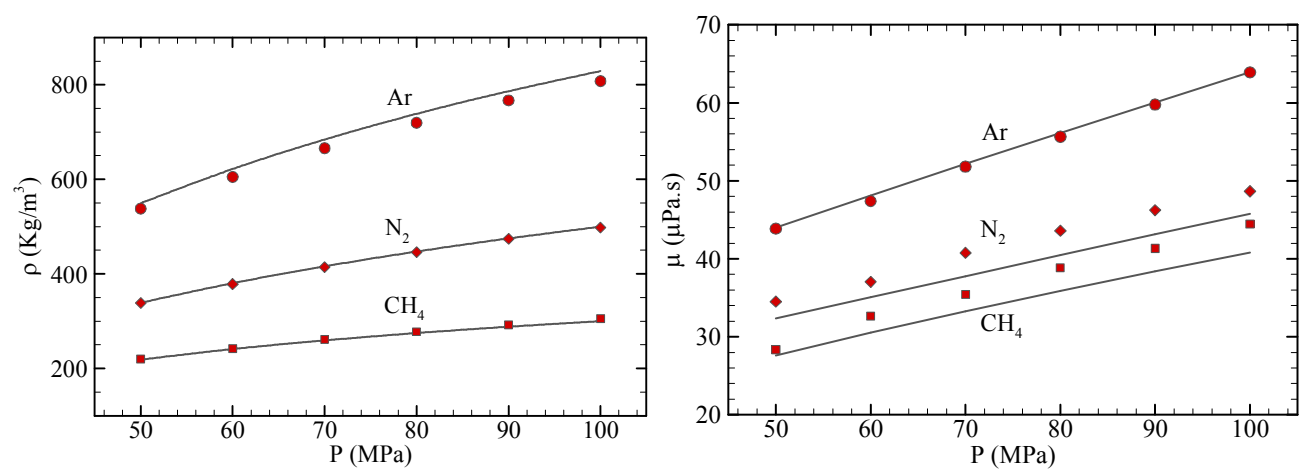

19

20

21

22

23

24

25

26

27

28

29

30

31

32

33

34

35

36

37

38

39

40

41

42

43

44

45

46

47

48

49

50

51

52

53

54

55

56

57

58

59

60 
Figure 7: Thermophysical properties of some n-alkanes along the vapor-liquid equilibrium curve. (a) Saturated density. (b) Vapor pressure. (c) Surface tension. (d) Saturated liquid viscosity. Filled circle: our MCCG model, open diamonds: Mejia et al.’s model [15, 36], solid lines: NIST Database [56].
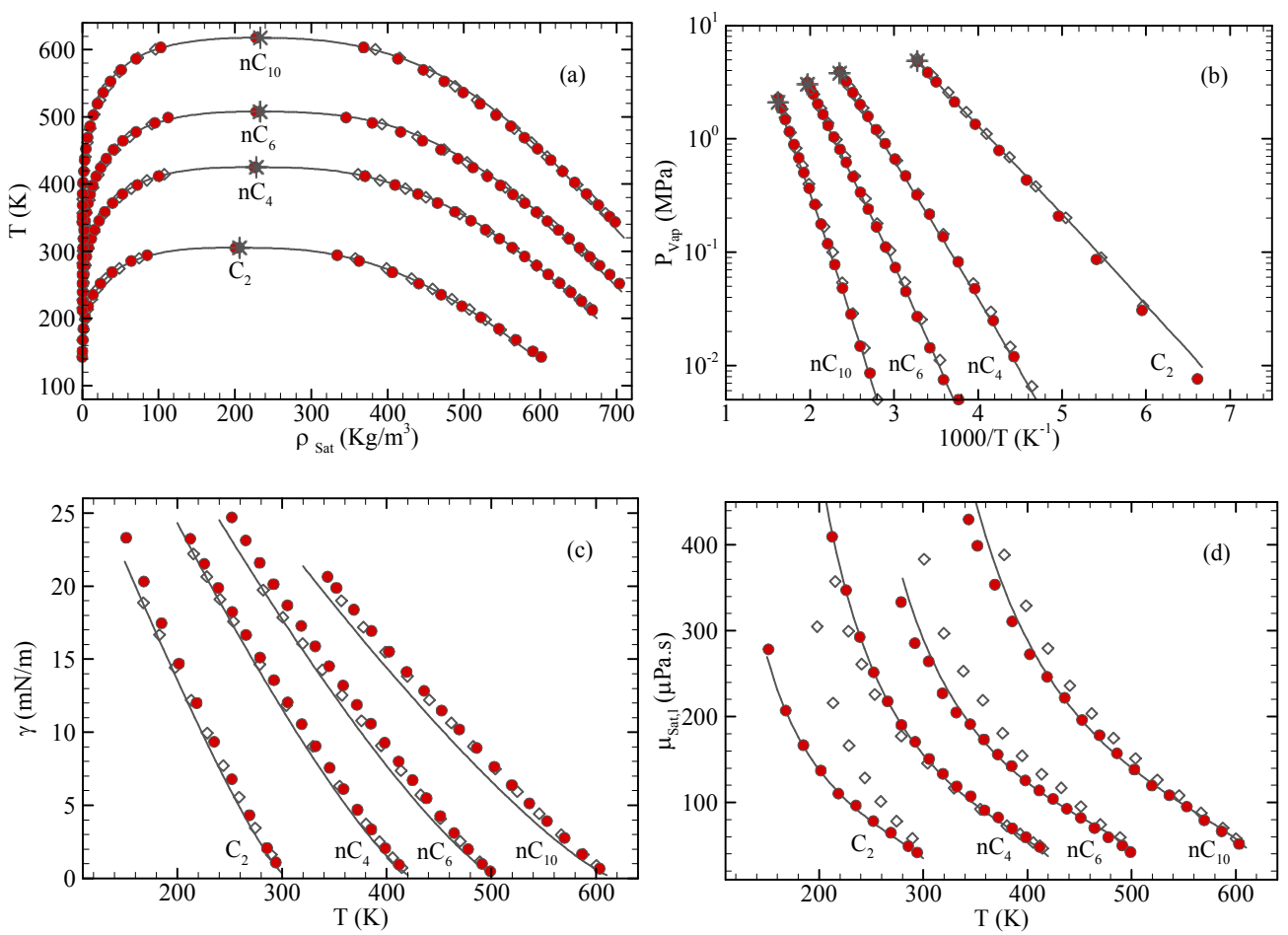

36

37

38

39

40

41

42

43

44

45

46

47

48

49

50

51

52

53

54

55

56 
Figure 8: Density (left figure) and viscosity (right figure) of some n-alkanes for various pressure at T=373K. Symbols: MCCG model. Solid lines: NIST database [56].
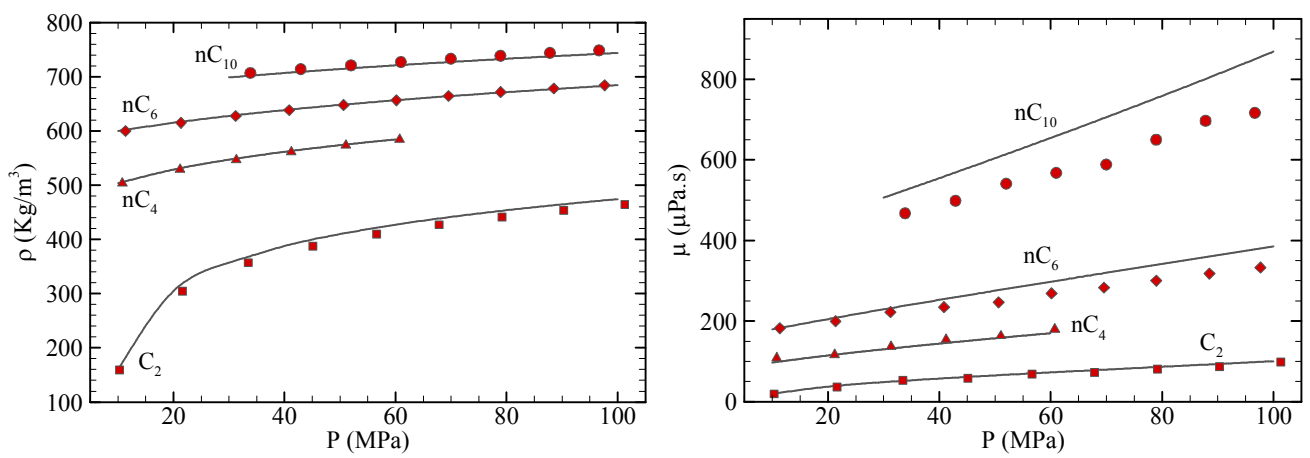
Figure 9: Thermophysical properties of $\mathrm{H}_{2} \mathrm{~S}, \mathrm{CO}_{2}$ and Toluene at the vapor-liquid equilibrium. (a) Saturated density. (b) Vapor pressure. (c) Surface tension. (d) Saturated liquid viscosity. Solid lines: experiments [56, 80-82], Filled circles: our MCCG model. Open diamonds: Herdes et al. [15]. Open squares: Werth et al. [72]. For clarification, symbols and lines associated $\mathrm{CO}_{2}$ in Fig. (d) have been shifted to the left by $50^{\circ} \mathrm{C}$.
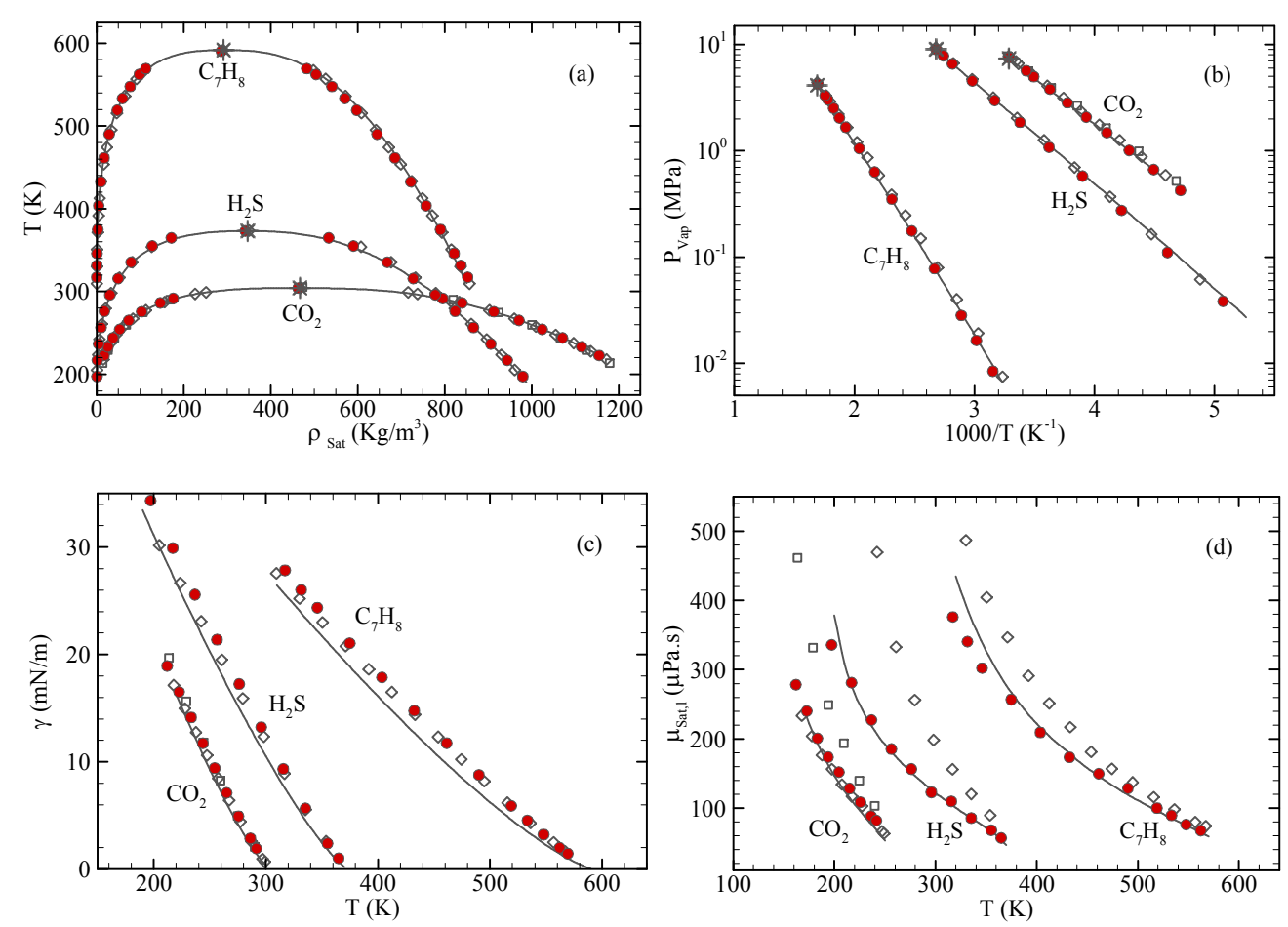
Figure 10: Pressure-composition phase diagrams of binary mixtures of simple fluids. (a) Argon + Krypton at $T=177.38 \mathrm{~K}$. (b) Krypton + Xenon at $T=190.03 \mathrm{~K}$. (c) Xenon + Methane at $T=189.78 K$. Symbols: MCCG model; solid lines: experiments [83-85].
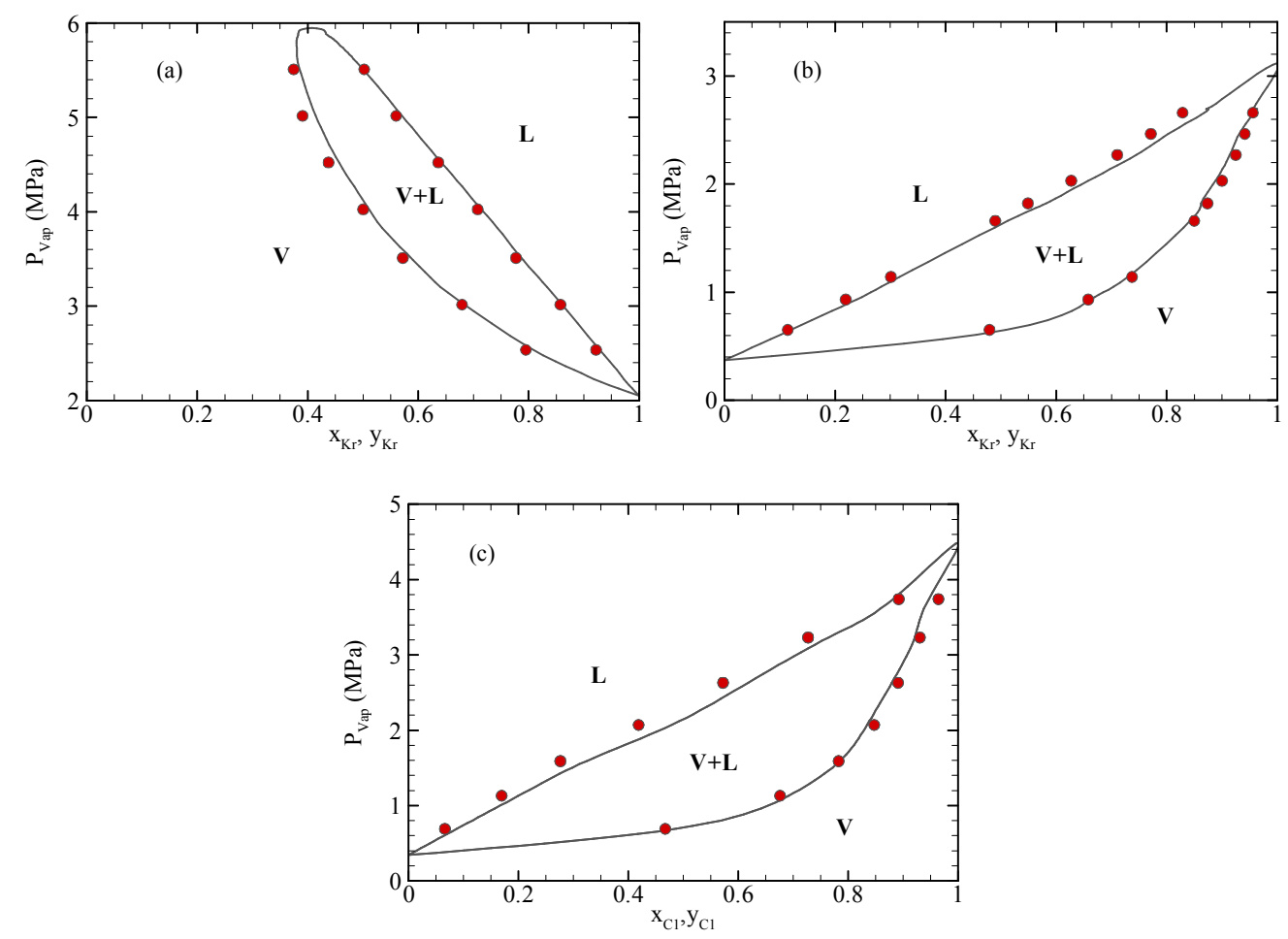
Figure 11: Density (left figure) and viscosity (right figure) of three binary hydrocarbons mixtures: $\mathrm{CH}_{4}+\mathrm{nC}_{4}$ at $T=377.59 \mathrm{~K}, \mathrm{CH}_{4}+\mathrm{nC}_{10}$ and $\mathrm{CH}_{4}+\mathrm{C}_{7} \mathrm{H}_{8}$ at $T=373 \mathrm{~K}$, for various pressures. Symbols: MCCG model; solid lines: experiments [56, 88-90].
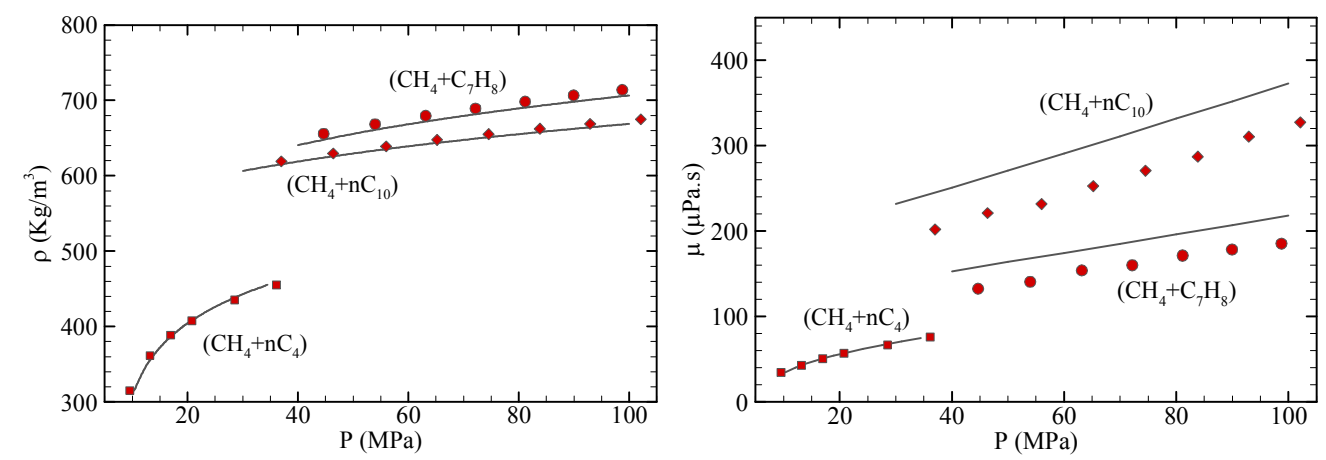

21

22

23

24

25

26

27

28

29

30

31

32

33

34

35

36

37

38

39

40

41

42

43

44

45

46

47

48

49

50

51

52

53

54

55

56

57

58

59

60 
Table 1: Parameters of the correlations, Eqs. (10-13), providing $\left(T_{c}^{*}, \rho_{s a t, l}^{*}, \omega, \mu^{r}\right)$ of the MCCG model

\begin{tabular}{|c|c|c|c|c|c|c|c|c|}
\hline \multicolumn{9}{|c|}{ Critical Temperature, $T_{c}^{*}$} \\
\hline$A_{0}$ & $A_{1}$ & $A_{2}$ & $A_{3}$ & $A_{4}$ & $A_{5}$ & $A_{6}$ & $A_{7}$ & $A_{8}$ \\
\hline-4.0219 & -0.6969 & 3.1689 & -0.5822 & -0.3909 & 1.4849 & 0.7195 & -3.1836 & 0.2520 \\
\hline \multicolumn{9}{|c|}{ Saturated liquid density, $\rho_{s a t, l}^{*}$} \\
\hline$B_{0}$ & $B_{1}$ & $B_{2}$ & $B_{3}$ & $B_{4}$ & $B_{5}$ & $B_{6}$ & $B_{7}$ & $B_{8}$ \\
\hline 0.3198 & -0.6815 & 0.2532 & -1.9621 & -0.4389 & -2.5033 & 0.1568 & -0.1756 & 0.5972 \\
\hline \multicolumn{9}{|c|}{ Acentric factor, $\omega$} \\
\hline \multicolumn{2}{|r|}{$C_{0}$} & \multicolumn{3}{|c|}{$C_{1}$} & \multicolumn{2}{|l|}{$C_{2}$} & \multicolumn{2}{|c|}{$C_{3}$} \\
\hline \multicolumn{2}{|c|}{-0.1574} & \multicolumn{3}{|c|}{-0.0008} & \multicolumn{2}{|l|}{0.3158} & \multicolumn{2}{|c|}{-0.4292} \\
\hline \multicolumn{9}{|c|}{ Reference viscosity, $\mu^{r}$} \\
\hline$D_{0}$ & $D_{1}$ & $D_{2}$ & $\begin{array}{l}D_{3} \\
\times 10^{3}\end{array}$ & $D_{4}$ & $\begin{array}{l}D_{5} \\
\times 10^{3}\end{array}$ & $D_{6}$ & $D_{7}$ & $D_{8}$ \\
\hline 0.7091 & -2.3960 & 0.8638 & 74.2270 & -0.2132 & -69.2268 & -1.2500 & 0.1229 & 0.9821 \\
\hline
\end{tabular}

46 
Table 2: Critical temperature, acentric factor, saturated liquid density and saturated liquid viscosity at $T=0.7 T_{c}$ for the studied compounds. Data comes from the NIST reference database and the literature [56, 80-82].

\begin{tabular}{|c|c|c|c|c|}
\hline Compound & $T_{c}(\mathrm{~K})$ & $\omega$ & $\begin{array}{c}\rho_{\text {sat }, 1}\left(T=0.7 T_{c}\right) \\
\left(\mathrm{kg} / \mathrm{m}^{3}\right)\end{array}$ & $\begin{array}{c}\mu_{\text {sat }, 1}\left(T=0.7 T_{c}\right) \\
(\mu \mathrm{Pa} / \mathrm{s})\end{array}$ \\
\hline $\mathrm{Ar}$ & 150.59 & -0.00219 & 1275.7 & 157.23 \\
\hline $\mathrm{Kr}$ & 209.48 & -0.00089 & 2196.2 & 228.09 \\
\hline $\mathrm{Xe}$ & 289.73 & 0.00363 & 2671.9 & 298.02 \\
\hline $\mathrm{N}_{2}$ & 126.19 & 0.03720 & 753.56 & 108.51 \\
\hline $\mathrm{CH}_{4}$ & 190.56 & 0.01142 & 388.38 & 76.221 \\
\hline $\mathrm{C}_{2}$ & 305.32 & 0.09950 & 505.25 & 118.13 \\
\hline $\mathrm{nC}_{4}$ & 425.13 & 0.20100 & 573.48 & 159.24 \\
\hline $\mathrm{nC}_{6}$ & 507.82 & 0.29900 & 599.25 & 174.97 \\
\hline $\mathrm{nC}_{10}$ & 617.70 & 0.48840 & 617.35 & 225.40 \\
\hline $\mathrm{C}_{7} \mathrm{H}_{8}$ & 591.75 & 0.26570 & 746.86 & 201.51 \\
\hline $\mathrm{CO}_{2}$ & 304.13 & 0.22394 & 1186.18 & 266.03 \\
\hline $\mathrm{H}_{2} \mathrm{~S}$ & 373.10 & 0.10050 & 858.25 & 173.15 \\
\hline
\end{tabular}


Table 3: Parameters of the MCCG model for a selection of compounds obtained from the parameterization described in Sect. III.

\begin{tabular}{|l|c|c|c|c|}
\hline Compound & $\mathrm{N}$ & $\lambda$ & $\varepsilon(\mathrm{J} / \mathrm{mol})$ & $\sigma(\AA)$ \\
\hline $\mathrm{Ar}$ & 1 & 13.93 & 1044.1 & 3.407 \\
\hline $\mathrm{Kr}$ & 1 & 13.43 & 1423.0 & 3.634 \\
\hline $\mathrm{Xe}$ & 1 & 14.22 & 2029.8 & 3.962 \\
\hline $\mathrm{N}_{2}$ & 1 & 14.08 & 879.6 & 3.609 \\
\hline $\mathrm{CH}_{4}$ & 1 & 11.06 & 1150.2 & 3.707 \\
\hline $\mathrm{C}_{2}$ & 2 & 11.62 & 1399.3 & 3.301 \\
\hline $\mathrm{nC}_{4}$ & 2 & 14.04 & 2212.7 & 3.969 \\
\hline $\mathrm{nC}_{6}$ & 3 & 13.38 & 2227.3 & 3.862 \\
\hline $\mathrm{nC}_{10}$ & 16.03 & 2799.9 & 4.111 \\
\hline $\mathrm{C}_{7} \mathrm{H}_{8}$ & 2 & 12.27 & 2438.2 & 3.658 \\
\hline $\mathrm{CO}_{2}$ & 2 & 16.93 & 1758.8 & 2.861 \\
\hline $\mathrm{H}_{2} \mathrm{~S}$ & & 10.96 & 1634.6 & 2.879 \\
\hline
\end{tabular}


Table 4: Computed critical parameters of the MCCG model for a selection of compounds. Experimental data come from the NIST database [56]. Values in parenthesis correspond to the uncertainties.

\begin{tabular}{|l|c|c|c|c|c|c|}
\hline \multirow{2}{*}{ Compound } & \multicolumn{2}{|c|}{ Critical temperature (K) } & \multicolumn{2}{c|}{ Critical pressure (MPa) } & \multicolumn{2}{c|}{ Critical density $\left(\mathrm{kg.m} \mathrm{m}^{-3}\right)$} \\
\cline { 2 - 7 } & Sim. & Expt. & Sim. & Expt. & Sim. & Expt. \\
\hline $\mathrm{Ar}$ & $150.3(0.4)$ & 150.69 & $4.90(0.17)$ & 4.863 & $534.8(5.5)$ & 535.60 \\
\hline $\mathrm{Kr}$ & $209.1(0.5)$ & 209.48 & $5.64(0.24)$ & 5.525 & $920.0(9.3)$ & 909.21 \\
\hline $\mathrm{Xe}$ & $289.58(0.7)$ & 289.73 & $6.04(0.21)$ & 5.842 & $1118.3(11.6)$ & 1102.9 \\
\hline $\mathrm{N}_{2}$ & $125.9(0.3)$ & 126.19 & $3.46(0.12)$ & 3.396 & $315.9(3.3)$ & 313.30 \\
\hline $\mathrm{CH}_{4}$ & $189.9(0.6)$ & 190.56 & $4.78(0.19)$ & 4.599 & $163.3(2.0)$ & 162.66 \\
\hline $\mathrm{C}_{2}$ & $304.9(0.5)$ & 305.32 & $4.82(0.10)$ & 4.872 & $200.6(2.9)$ & 206.18 \\
\hline $\mathrm{nC}_{4}$ & $424.9(0.8)$ & 425.13 & $3.93(0.09)$ & 3.796 & $225.8(2.2)$ & 228.00 \\
\hline $\mathrm{nC}_{6}$ & $507.5(0.8)$ & 507.82 & $3.14(0.06)$ & 3.034 & $227.9(1.7)$ & 233.18 \\
\hline $\mathrm{nC}_{10}$ & $617.4(0.7)$ & 617.70 & $2.26(0.08)$ & 2.103 & $227.7(1.2)$ & 233.34 \\
\hline $\mathrm{C}_{7} \mathrm{H}_{8}$ & $590.3(0.9)$ & 591.75 & $4.24(0.10)$ & 4.126 & $286.5(1.6)$ & 291.99 \\
\hline $\mathrm{CO}_{2}$ & $304.1(0.4)$ & 304.13 & $7.52(0.17)$ & 7.377 & $463.6(2.5)$ & 467.60 \\
\hline $\mathrm{H}_{2} \mathrm{~S}$ & $373.1(0.6)$ & 373.10 & $8.96(0.12)$ & 9.000 & $341.9(5.3)$ & 347.28 \\
\hline
\end{tabular}


Table 5: Soret coefficients of $\mathrm{Ar}-\mathrm{Kr}$ and $\mathrm{nC}_{5}+\mathrm{nC}_{10}$ mixtures at ambient pressure.

\begin{tabular}{|c|c|c|c|c|}
\hline $\begin{array}{c}\text { Mixture } \\
(\text { molar fraction })\end{array}$ & $\begin{array}{c}\text { Temperature } \\
\text { in K }\end{array}$ & $\begin{array}{c}\text { Experiments } \\
{[98-99]}\end{array}$ & $\begin{array}{c}\text { FG model } \\
{[98-99]}\end{array}$ & MCCG model \\
\hline $\begin{array}{c}\mathrm{Ar}-\mathrm{Kr} \\
\left(x_{\mathrm{Ar}}=0.679\right)\end{array}$ & 95.20 & $2.78 \pm 0.7$ & $2.24 \pm 0.4$ & $2.32 \pm 0.2$ \\
\hline $\begin{array}{c}\mathrm{Ar}-\mathrm{Kr} \\
\left(x_{\mathrm{Ar}}=0.784\right)\end{array}$ & 93.00 & $2.10 \pm 0.3$ & $2.07 \pm 0.7$ & $2.47 \pm 0.2$ \\
\hline $\begin{array}{c}\mathrm{nC}_{5}-\mathrm{nC}_{10} \\
\left(x_{\mathrm{nC}_{5}}=0.200\right)\end{array}$ & 300.15 & $3.79 \pm 0.3$ & $2.49 \pm 0.6$ & $2.62 \pm 0.6$ \\
\hline $\begin{array}{c}\mathrm{nC}_{5}-\mathrm{nC}_{10} \\
\left(x_{\mathrm{nC}_{5}}=0.500\right)\end{array}$ & 300.15 & $3.27 \pm 0.2$ & $2.92 \pm 0.5$ & $2.88 \pm 0.4$ \\
\hline $\begin{array}{c}\mathrm{nC}_{5}-\mathrm{nC}_{10} \\
\left(x_{\mathrm{nC}_{5}}=0.800\right)\end{array}$ & 300.15 & $3.53 \pm 0.3$ & $2.81 \pm 0.4$ & $2.82 \pm 0.6$ \\
\hline
\end{tabular}


Table of Contents Graphic:

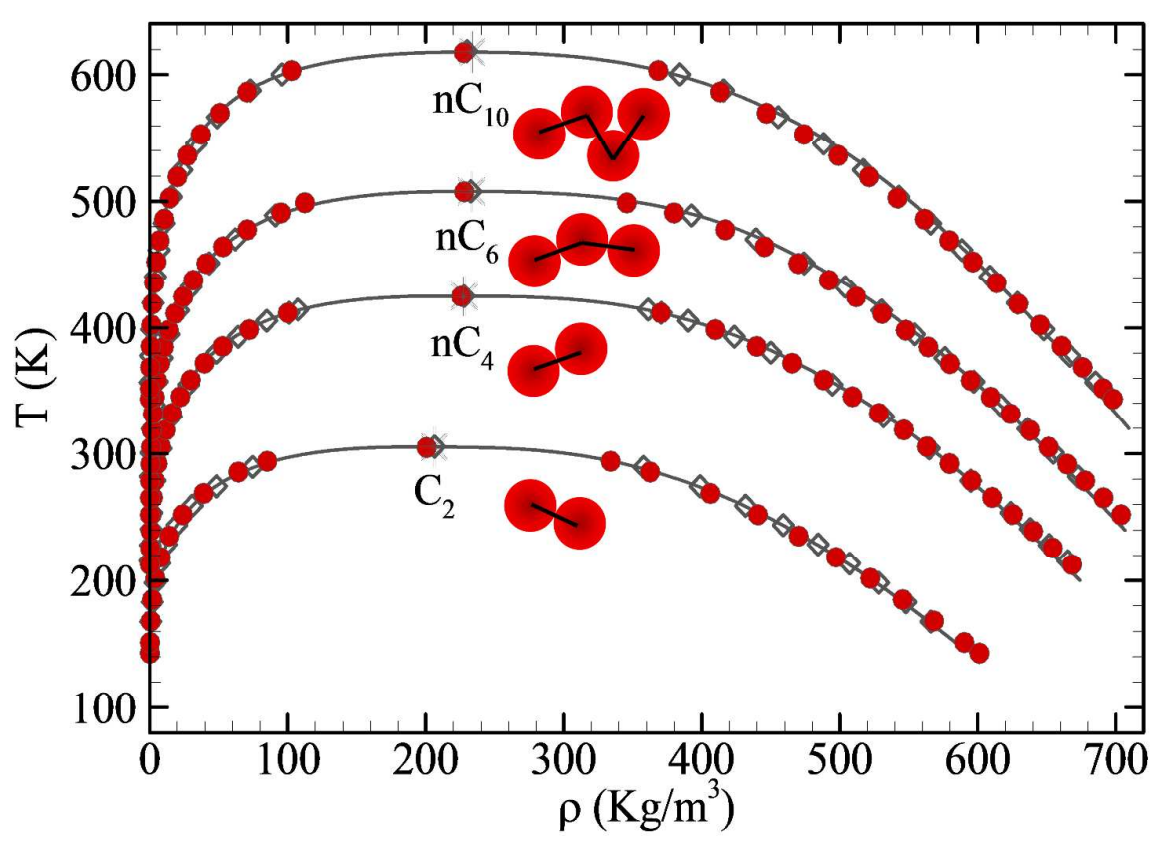

1

2

3

4

5

6

7

10

11

12

13

14

15

16

17

18

19

20

21

22

23

24

25

26

27

28

29

30

31

32

33

34

35

36

37

38

39

40

41

42

43

44

45

46

47

48

49

50

51

52

53

54

55

56

57

58

59

60 